\title{
Quantifying the effects of environmental factors on wildfire burned area in the south central US using integrated machine learning techniques
}

\author{
Sally S.-C. Wang ${ }^{1, \mathrm{a}}$ and Yuxuan Wang ${ }^{1}$ \\ ${ }^{1}$ Department of Earth and Atmospheric Sciences, University of Houston, Houston, Texas 77024, USA \\ ${ }^{a}$ now at: Atmospheric Sciences and Global Change Division, Pacific Northwest National Laboratory, \\ Richland, Washington, 99354, USA
}

Correspondence: Yuxuan Wang (ywang246@central.uh.edu)

Received: 1 October 2019 - Discussion started: 4 November 2019

Revised: 14 July 2020 - Accepted: 21 July 2020 - Published: 28 September 2020

\begin{abstract}
Occurrences of devastating wildfires have been increasing in the United States for the past decades. While some environmental controls, including weather, climate, and fuels, are known to play important roles in controlling wildfires, the interrelationships between these factors and wildfires are highly complex and may not be well represented by traditional parametric regressions. Here we develop a model consisting of multiple machine learning algorithms to predict $0.5^{\circ} \times 0.5^{\circ}$ gridded monthly wildfire burned area over the south central United States during 2002-2015 and then use this model to identify the relative importance of the environmental drivers on the burned area for both the winter-spring and summer fire seasons of that region. The developed model alleviates the issue of unevenly distributed burned-area data, predicts burned grids with area under the curve (AUC) of 0.82 and 0.83 for the two seasons, and achieves temporal correlations larger than 0.5 for more than $70 \%$ of the grids and spatial correlations larger than $0.5(p<0.01)$ for more than $60 \%$ of the months. For the total burned area over the study domain, the model can explain $50 \%$ and $79 \%$ of the observed interannual variability for the winter-spring and summer fire season, respectively. Variable importance measures indicate that relative humidity $(\mathrm{RH})$ anomalies and preceding months' drought severity are the two most important predictor variables controlling the spatial and temporal variation in gridded burned area for both fire seasons. The model represents the effect of climate variability by climate-anomaly variables, and these variables are found to contribute the most to the magnitude of the total
\end{abstract}

burned area across the whole domain for both fire seasons. In addition, antecedent fuel amounts and conditions are found to outweigh the weather effects on the amount of total burned area in the winter-spring fire season, while fire weather is more important for the summer fire season likely due to relatively sufficient vegetation in this season.

\section{Introduction}

Wildfire is an important process maintaining the balance of terrestrial ecosystems. Wildfire occurrence is controlled by a complex interaction among fuel, weather, and climate (Bowman et al., 2009; Pausas and Keeley, 2009). In recent decades, many regions of the world have experienced an increase in frequency and intensity of wildfires, which may be possibly connected to changes in regional climate (Balshi et al., 2009; Barbero et al., 2015; Carvalho et al., 2008; Flannigan et al., 2009; Westerling et al., 2006; Westerling, 2016). More intense and more frequent wildfire activities not only heighten ecosystem vulnerability but also cause poor air quality (Jaffe et al., 2008; Pellegrini et al., 2017; Wang et al., 2018; Yue et al., 2015). Thus, it is imperative to understand how wildfires would respond to changes in environmental factors in a warming climate.

Previous studies revealed the importance of several environmental factors for wildfires. Fuel availability and composition across regions can affect fire developments such as fire likelihood and spread efficiency (Nunes et al., 2005; Parks 
et al., 2012). Weather influences fuel moisture by changing precipitation and humidity, and they control fire spread through winds. Long-term climate change can alter both fuel and weather conditions, for example by adjusting vegetation distributions and the frequency of fire-favorable atmospheric conditions (Heyerdahl et al., 2008; Keyser and Westerling, 2017; Morgan et al., 2008; Zubkova et al., 2019), therefore changing fire regimes. Past studies also highlighted that the complex interplay between fuel, weather, climate, and wildfires can vary depending on spatial scale, fire size, region, and season. For instance, the relationships between fire activity and the environmental controls can exhibit complex nonlinearities across the spatial scale gradient (Peters et al., 2004). Fuel and topography mainly regulate fires at a local scale, while weather and climate control fires at a broad spatial scale (Parks et al., 2012). In terms of fire size, it was found that the major controlling factors could shift from fuel and topography to weather as fire size increases in boreal forests (Liu et al., 2013; Fang et al., 2015). In the western Mediterranean Basin, where land heterogeneity is large, influences of fuel can outweigh influences of climate and weather on large fires (Fernandes et al., 2016). Therefore, it is challenging to examine the relative importance of the environmental drivers on wildfires due to the complex interrelationships among them.

One common method to explain the relationships between fire regimes (e.g., fire sizes or fire occurrences) and environmental factors is regression. This method is also used to evaluate the relative importance of different environmental controls (Littell et al., 2009; Slocum et al., 2010; Parisien et al., 2011; Yue et al., 2013; Liu and Wimberly, 2015; Fernandes et al., 2016). Among a wide range of regression techniques used, nonparametric machine learning algorithms have emerged as an important tool to predict wildfires because they rely on fewer pre-assumptions about the data. Bedia et al. (2014) used nonparametric multivariate adaptive regression splines (MARSs) to model the monthly burned area for the phytoclimatic zones in Spain of sizes ranging from $25 \mathrm{~km} \times 25 \mathrm{~km}$ to $100 \mathrm{~km} \times 100 \mathrm{~km}$. Amatulli et al. (2013) used two machine learning approaches - random forest (RF) and MARS - to estimate monthly burned area in five countries in Europe with a spatial resolution ranging from $300 \mathrm{~km} \times 300 \mathrm{~km}$ to $1000 \mathrm{~km} \times 1000 \mathrm{~km}$. In these studies, the machine learning methods were used to estimate total burned area aggregated over a large-scale domain, e.g., on an ecoregion or a country scale (Table S1 in the Supplement). However, fewer studies have explored the utility of machine learning methods in resolving the within-domain and grid-level relationships between fires and the environmental drivers. A particular challenge in predicting burned area of fires at the grid level across a broad region relates to the uneven distribution of burned area both spatially and temporally, where the number of grids of large burned area is much smaller than the number of those with small or zero burned areas. For example, Steel et al. (2015) showed that

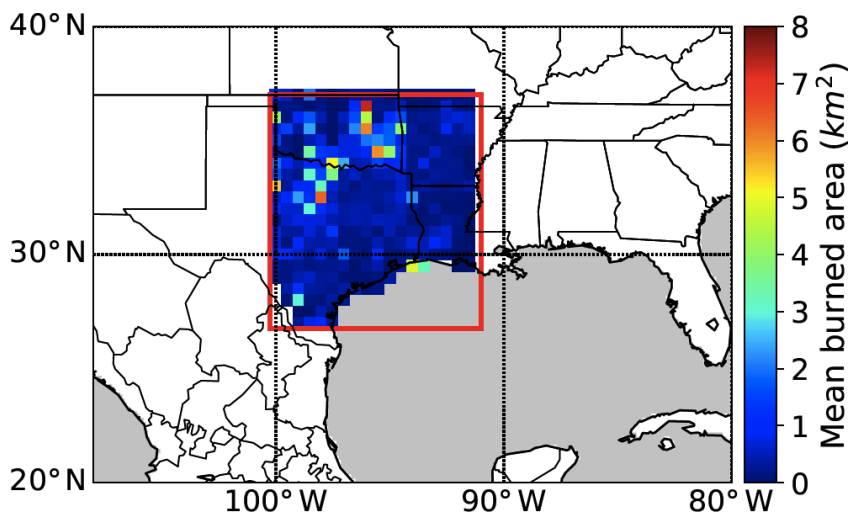

Figure 1. The colored grid boxes show the averaged burned area for the winter-spring and summer fire seasons during 2002-2015 from Fire Program Analysis Fire-Occurrence Database (FPA-FOD). The red box denotes the south central US domain.

for fires in California, small fires ( $<25$ ha each) contributed to $87 \%$ of the total number of grids burned but only $17 \%$ of the total burned area, whereas large fires ( $>150$ ha each) accounted for only $3 \%$ of the total number of burned grids but made up $64 \%$ of the total burned area. Thus, at the grid level the majority class is non-burn wildlands or small fires, while the minority class is large fires. As most data-driven regression algorithms, parametric or nonparametric, would favor the majority class, large fires will be underpredicted for gridlevel predictions.

In this study, we develop a model consisting of multiple machine learning techniques to predict wildfire burned area at the grid level over the vegetation-rich and thus fire-prone region of the south central United States (US), which encompasses four states - Texas, Oklahoma, Louisiana, and Arkansas - as shown in Fig. 1. The study region is chosen for several reasons. First, this region is composed of similar vegetation types, which are plains and oak-hickory forests. Second, the vegetation-rich region of the south central US is fire-prone and has experienced periodically large wildfires in recent years, such as the 2011 Texas fires (Long et al., 2013; Nielsen-Gammon, 2012), but the region as a whole has been much less studied compared to the western US. Third, this region is projected to have the highest risk of wildfires in 2031-2050 across the continental US (An et al., 2015; Fann et al., 2018). In terms of the prediction method, the integrated machine learning model aims at mitigating the problem of the uneven distribution of burned-area data and improving the accuracy of predicting wildfire burned area at a grid scale of $0.5^{\circ} \times 0.5^{\circ}$. Using the prediction model developed here, the goal of this paper is to estimate the relative importance of different environmental factors on wildfire burned area in the study region, which would be useful for future fire prediction as well as understanding the linkage between wildfires and climate change. 
The study period is from 2002 to 2015 . For each year, we predict gridded wildfire burned area at the monthly scale for the typical bimodal wildfire seasons over the region (Fig. S1 in the Supplement): the winter-spring fire season from January to April and summer fire season from July to September (Zhang et al., 2014). Wildfires during the winter-spring wildfire season are typically associated with dry and strong winds resulting from large-scale low-pressure systems (Heilman et al., 1998; Jones et al., 2013), while wildfires in the summer are mostly driven by the abundance of dry or dead vegetation produced from the dry season (Jones et al., 2013). These two seasons contribute $76 \%$ of the annual total burned area, indicating that natural environmental conditions in these months are most conducive for wildfires. While wildfires do occur outside the fire seasons, their lower frequency implies that nonnatural factors (e.g., human actions) can be relatively more important. As our study does not focus on human factors, we choose to exclude other months of the year.

The rest of the paper is organized as follows: Sect. 2 introduces data incorporated into the model. Section 3 describes the developed model and validation method. Section 4 presents the results of model validation and evaluation. In Sect. 5, we analyze the relative importance of individual variables and the environmental controls at different spatial scales. Discussion and conclusion are given in Sect. 6.

\section{Data}

\subsection{Wildfire burned area}

The model predicts wildfire burned area at a grid scale of $0.5^{\circ} \times 0.5^{\circ}$ over the study region. Wildfire burned area is chosen as the target variable because it is a widely used parameter for quantitative assessment of fire danger and fire impact (Amatulli et al., 2013; Balshi et al., 2009; Yue et al., 2013). Wildfire information over the study period (2002-2015) is obtained from the Fire Program Analysis Fire-Occurrence Database (FPA-FOD). The FPA-FOD collects daily wildfire reports from federal, state, tribal, and local governments. The dataset includes wildfire burned area, fire location in longitude and latitude, and fire discovery date from 1992 to 2015 (Short, 2017). The FPA-FOD fire data exclude prescribed fires except for the prescribed fires that escape their planned perimeters and become wildfires. A known caveat of this database is that it does not include some small fires that occur on private lands. Short (2014) reported that for the period of 1992-1997 the national total number of wildfires from the FPA-FOD is about $30 \%$ lower compared to that from the US Department of Agriculture Forest Service (USFS) Wildfire Statistics, although the national total burned area is consistent between the two datasets. Thus, our model will not be able to predict those small fires missing from the FPA-FOD as such information is not in the training dataset.
The FPA-FOD wildfire data are point data at a daily time step. As the prediction model deals with the monthly total burned area at a spatial resolution of $0.5^{\circ} \times 0.5^{\circ}$, we aggregate the daily point burned area into $0.5^{\circ} \times 0.5^{\circ}$ grid cells based on fire longitude and latitude and sum the burned area in each grid by month. The resulting dataset of monthly burned area has nearly $70 \%$ of the grids with a burned area of less than 10 ha or non-burned. To reduce skewness and improve data symmetry, we apply the log transformation function $\ln (x+1)$, where $x$ is the gridded monthly total burned area. The log-transformed burned area is the target variable of the model.

\subsection{Predictor variables}

Based on previously published studies, we collect a number of predictor variables that are thought to influence wildfire burned area (Fang et al., 2015; Keyser and Westerling, 2017; Liu and Wimberly, 2015; Riley et al., 2013; Yue et al., 2013) and group them into four categories of environmental controls (Table 1): weather, climate, fuel, and fixed geospatial variables. These predictor variables are listed in Table 1 and described below. All the variables, including continuous and discrete thematic variables, are resampled to a spatial resolution of $0.5^{\circ} \times 0.5^{\circ}$ by the nearest-neighbor resampling method (Baboo and Devi, 2010). The nearest-neighbor resampling method assigns a value to the new grid according to the value of the original grid closest to the center of the new grid. The resampling method has the advantages of being efficient and not changing any value from the original dataset.

\subsubsection{Weather variables}

The meteorological data are obtained from the North American Regional Reanalysis (NARR) with a spatial resolution of $32 \mathrm{~km} \times 32 \mathrm{~km}$ (Mesinger et al., 2006). The weather variables include the monthly total accumulated precipitation and the monthly means of the following variables: daily precipitation, daily average and maximum temperature, zonal $(U)$ and meridional $(V)$ components of wind at $10 \mathrm{~m}$, and daily average and minimum relative humidity $(\mathrm{RH})$. In order to select extreme conditions that are likely to induce wildfires on a sub-monthly timescale, we also include the number of consecutive days without rainfall within a month, which is based on daily precipitation from the NARR data. Another extreme weather pattern conducive for wildfires is drought (Gudmundsson et al., 2014; Riley et al., 2013; Turco et al., 2017). Drought depicts the extreme condition of water deficit in the coupled land-atmosphere system that can be driven not only by lack of precipitation but also by excessive evaporation. We use the Standard Precipitation and Evaporation Index (SPEI) to represent drought intensity (Vicente-Serrano et al., 2009). The SPEI incorporates both precipitation and potential evapotranspiration to estimate climatic water bal- 


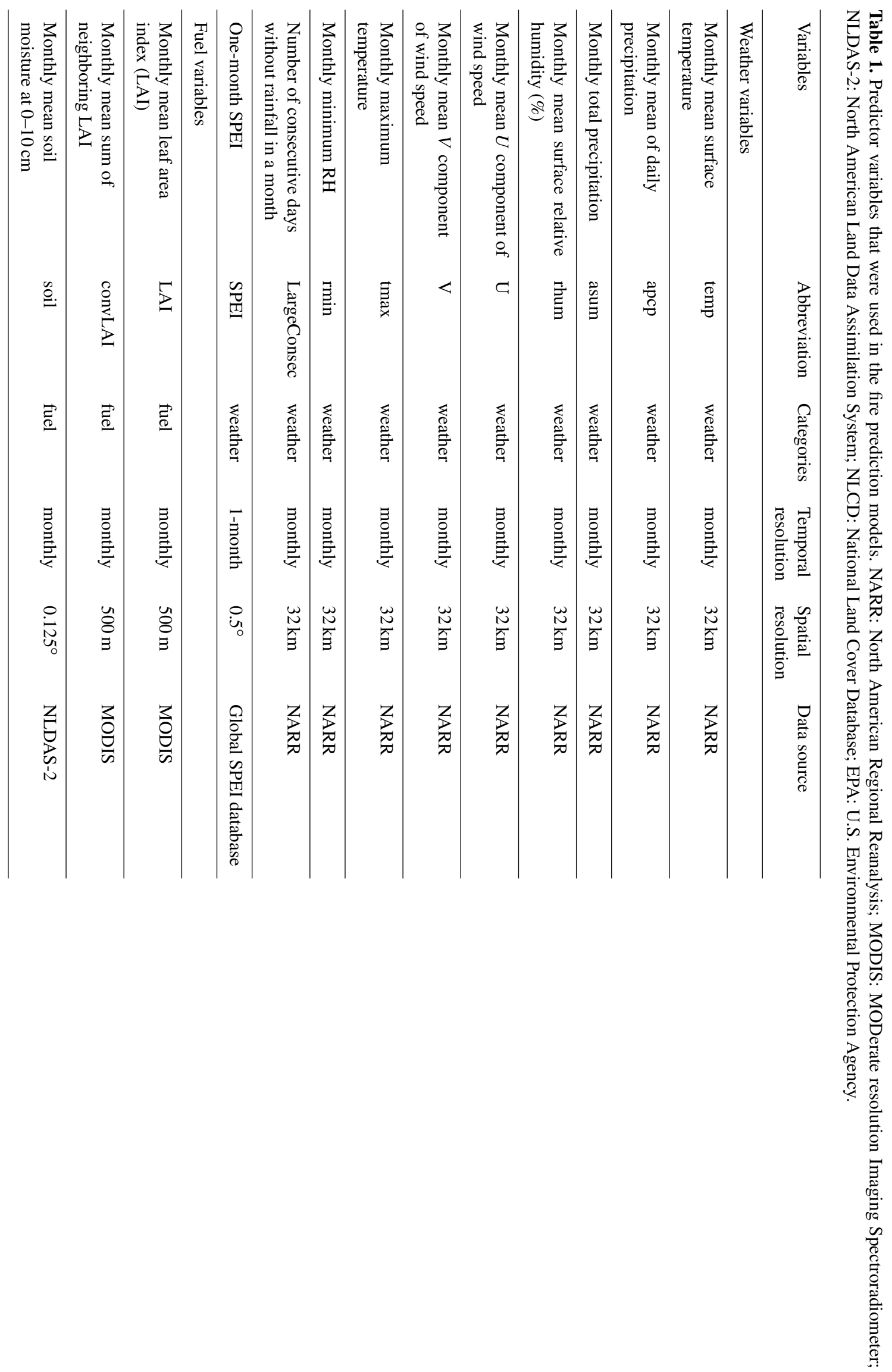




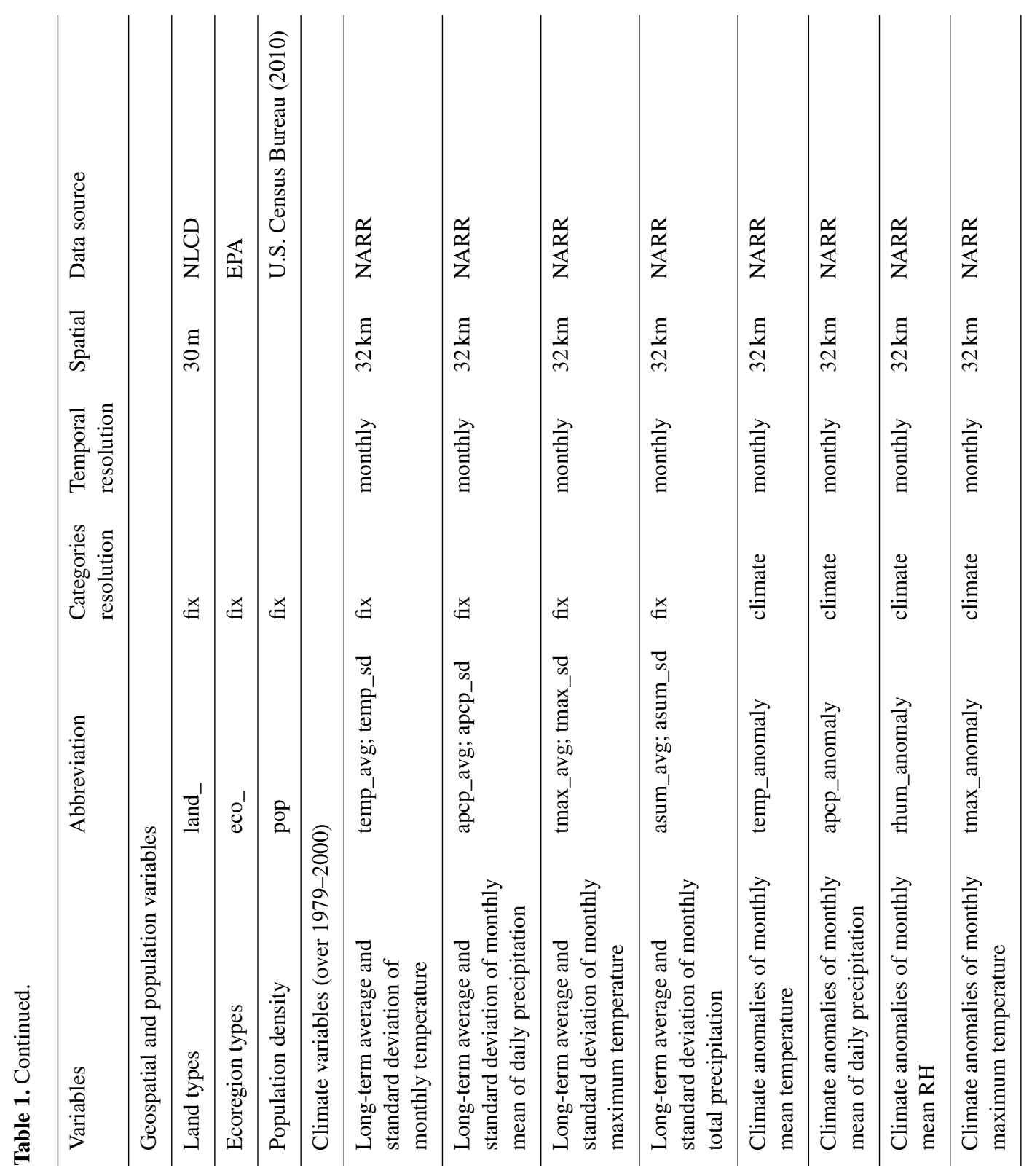




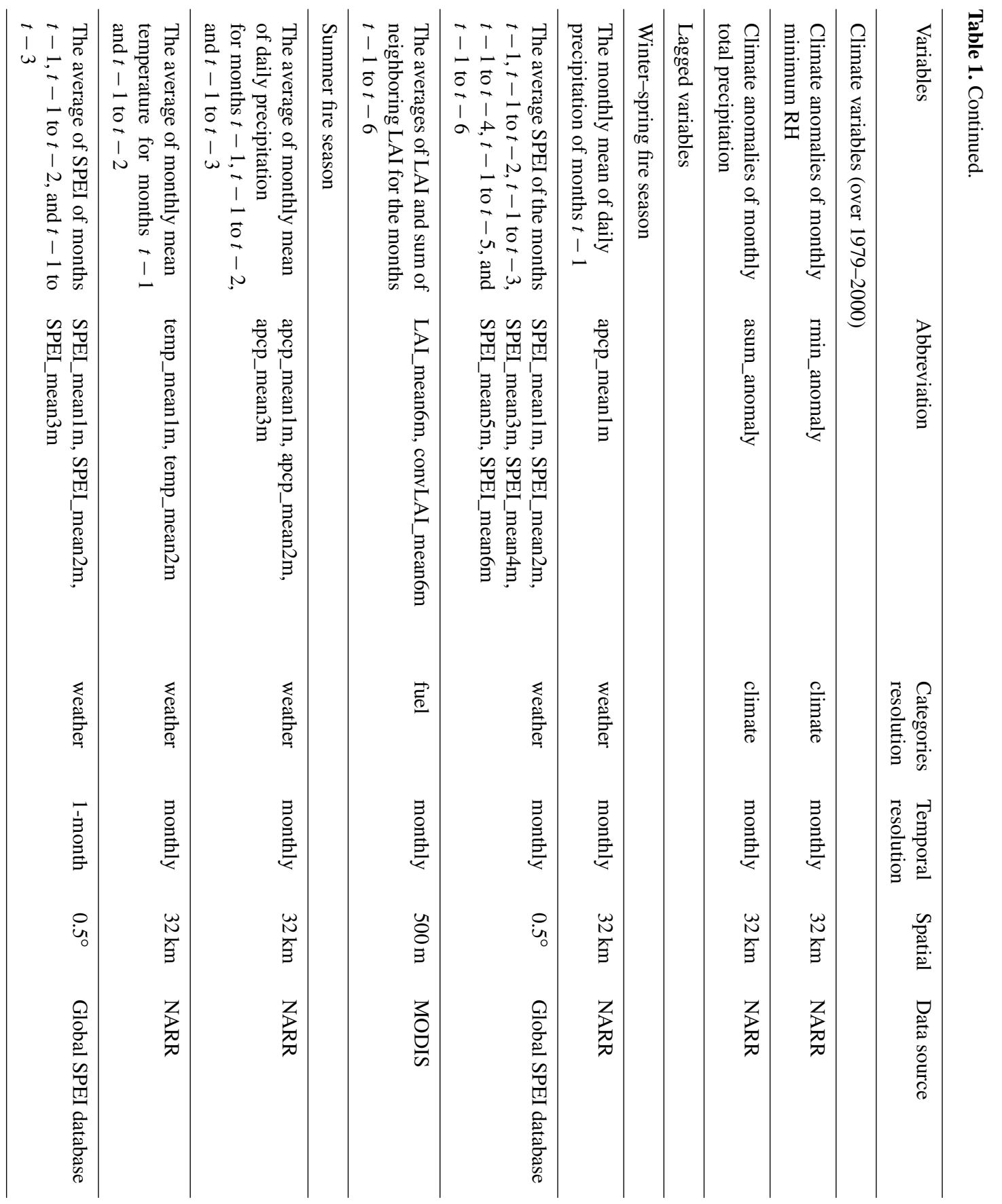


ance at different timescales (1 to 48 months). In this study, we use the 1-month SPEI from the global SPEI database (http://spei.csic.es/database.html, last access: 25 July 2017) with a spatial resolution of $0.5^{\circ} \times 0.5^{\circ}$. Positive values of SPEI represent wetter than normal conditions and negative values indicate conditions that are drier than normal.

Weather conditions in the preceding months are also known to influence fire development. For example, an increase in precipitation in the preceding months can promote biomass growth and provide fuels for a widespread of larger wildfires in a later month (Fréjaville and Curt, 2017; Littell et al., 2009). To consider such lagged effects, for a given month $t$, we calculate the averages of the aforementioned weather variables from the months $t-1$ to $t-12$. We then include those lagged variables that have correlation coefficients $(r)$ larger than 0.5 with wildfire burned area of month $t$ but are not strongly correlated with the same variables of month $t$ $(r<0.5)$. For the winter-spring fire season, the antecedent variables that pass this criterion are the monthly mean of daily precipitation of months $t-1$ and the average SPEI of the months $t-1, t-1$ to $t-2, t-1$ to $t-3, t-1$ to $t-4$, $t-1$ to $t-5$, and $t-1$ to $t-6$. For the summer fire season, the selected antecedent variables are the average of monthly mean temperature for months $t-1$ and $t-1$ to $t-2$, monthly mean of daily precipitation for months $t-1, t-1$ to $t-2$ and $t-1$ to $t-3$, and mean SPEI of months $t-1, t-1$ to $t-2$, and $t-1$ to $t-3$.

\subsubsection{Climate variables}

Inputs of climate variables to the model include both climate anomalies and 22-year (1979-2000) means and standard deviations of selected meteorological variables from the NARR data. Here climate anomalies refer to the departure of monthly mean meteorological variables from their longterm averages over 1979-2000, thereby representing the effects of climate on meteorological conditions. The climate anomalies are calculated for the monthly total precipitation and monthly means of daily average precipitation, daily average and maximum temperature, and average and minimum $\mathrm{RH}$. The long-term average and standard deviation of meteorological variables characterize the spatial and temporal patterns of the mean climate conditions, which can determine the typical vegetation of the study region and hence influence fire occurrence and size (Keyser and Westerling, 2017). We use the 22-year means and standard deviations of monthly total accumulated precipitation and monthly means of daily average and maximum temperature, and daily average precipitation. As climatological means and standard deviations do not vary with time, they are grouped with the geospatial variables later in the study as the category of fixed variables.

\subsubsection{Fuel variables}

Fuel variables are selected to estimate the fuel effect on burned area and these variables include monthly mean of leaf area index (LAI), sum of neighboring LAI, and soil moisture. The LAI is the ratio of the total one-sided area of green leaf area per unit ground surface area, which has been widely used to describe the structural property of a plant canopy (Watson, 1947; Chen and Black, 1992). Additionally, LAI is correlated with important metrics of canopy fuel loads, such as canopy bulk density (Keane et al., 2005; Steele-Feldman et al., 2006). The monthly mean LAI at a spatial resolution of $500 \mathrm{~m}$ is obtained from MODerate resolution Imaging Spectroradiometer (MODIS) instruments (Myneni et al., 2015). Besides local LAI values, to capture the effects of spatial autocorrelations, we consider each grid cell as the center of a three-by-three grid matrix and compute the summation of the LAI from the center grid's eight neighboring grids. This summation is referred to as the "sum of neighboring LAI" and included as a predictor variable. The lagged effects of fuel buildup in the preceding months are expected to influence wildfire occurrence and size. Using the same criteria to select antecedent weather variables (Sect. 2.2.1), the averages of LAI and sum of neighboring LAI for the months $t-1$ to $t-6$ are selected as antecedent fuel variables for the winterspring fire season, but no such variables are included for the summer fire season because none passes the selection criteria.

Fuel moisture is a critical property for evaluating fire danger. As fuel moisture data are limited, soil moisture is often used as an indicator of fuel moisture because of the strong correlation between the two (Krueger et al., 2016). Here, we use the monthly surface soil moisture $(0-10 \mathrm{~cm})$ from the Noah land-surface model for Phase 2 of the North American Land Data Assimilation System (NLDAS-2) with a spatial resolution of $0.125^{\circ} \times 0.125^{\circ}$ to represent the influence of fuel moisture (Xia et al., 2012; Mocko, 2013).

\subsubsection{Geospatial variables and population}

Lastly, population and two geospatial variables are used as predictors, including ecoregions and land cover types which are chosen to capture the effects of land use and ecosystem similarity on wildfire burned area. Land cover mainly describes the physical material at the surface of the earth. The land cover data at the spatial resolution of $30 \mathrm{~m}$ are obtained from the 2011 Landsat-derived land cover map from the National Land Cover Database (NLCD) (https://www.mrlc.gov, last access: 20 April 2018) (Homer et al., 2020). The ecoregion data are obtained from the United States Environmental Protection Agency (U.S. EPA) (https://www.epa.gov/eco-research/ecoregions, last access: 20 April 2018) (Omernik, 1995; Omernik and Griffith, 2014). The ecoregions denote areas of similarity in the mosaic of biotic, abiotic, terrestrial, and aquatic ecosys- 
tem components. Population density data in the year 2010 from the U.S. Census Bureau (https://www.census.gov/geo/ maps-data/data/tiger.html, last access: 1 September 2018) (U.S. Census Bureau, 2010) are used to estimate the influence of present-day human management practices and human activities on wildfires.

\section{Model}

\subsection{Model description}

One major challenge in wildfire prediction is the highly uneven distribution of burned area where the number of grids with large burned areas is typically much smaller than the number of grids with small or zero burned areas (Fig. S2a). For the study region (red box in Fig. 1), grids without any fire occurrence in combination with those of only small fires ( $<25$ ha) take up $79 \%$ of the total number of the grids but correspond to only $1 \%$ of the total burned area. By contrast, grids with the large burned area ( $>150 \mathrm{ha}$ ) account for $84 \%$ of the total burned area but only $6 \%$ of the total number of grids. For such unevenly distributed data, standard machine learning methods usually favor the majority class (i.e., nonburned or small fires), leading to the low prediction accuracy of the minority class (i.e., large fires) (Krawczyk, 2016). To alleviate the low bias toward large fires, we develop a model consisting of multiple steps that address the uneven data issue.

Figure 2 demonstrates the structures and processes of our model, which has four steps and uses three machine learning algorithms. First, for each data grid, given the predictor variables, we use the quantile regression forest (QRF) to predict a distribution of burned area at the targeted percentiles, which are chosen at 45, 55, 65, 85, 95, and 99 in this step. The percentiles here refer to the relative position of the predicted burned area in the cumulative distribution of all the burned-area data and they are chosen to include the whole conditional distribution. Second, for all the grids, we predict if a grid burns or not by using the logistic regression model and the same set of predictor variables as in the first step. Third, for the grids that are predicted to burn, instead of predicting burned area directly, we use an RF model to predict the percentile of burned area relative to the training set. After all the predicted-burn grids obtain their predicted percentiles of burned area by the RF, the test dataset is divided into six subgroups according to their predicted percentiles: $\{(39,49)$, $(50,59),(60,69),(70,79),(80,89),(>=90)\}$. The percentile groups are chosen to align with the six percentiles in the first step. The first three percentiles correspond to the median of the first three percentile groups. For example, the first percentile group $(39,49)$ has a median percentile of 45 , the first percentile of predicted wildfire burned area from the first step. The last three percentiles $(85,95$, and 99) from the first step correspond to the last three percentile groups of $(70,79)$,
$(80,89)$, and ( $>=90)$, respectively, although they lie outside the upper bounds of corresponding subgroups. This is based on the assumption that grids with the larger predicted burned area (predicted percentile $>70$ ) in the testing set will have more right-shifted burned-area distributions than the distributions of the whole training set, as shown in Fig. S3. In step 4, for the grids in a given subgroup, they are assigned to the burned-area value at the corresponding percentiles as determined by the predicted distribution generated from the first step. Specifics of the machine learning algorithms and technical details of the prediction model are described in the subsections below.

Our approach alleviates the issue of unevenness data for two reasons. First, the majority of zero-burn grids are separated by the second step. Second, for the grids predicted to burn, we predict the relative position (i.e., percentiles) of the burned area based on the training set. As Fig. S2 and Table S2 show, the distribution of percentiles is less skewed compared to the burned-area distribution. Thus, the unevenness of the burned area is less severe when predicting the percentiles than predicting the burned area directly. Given the possible collinearity between the predictor variables, we choose the logistic model and RF model, which are shown to work reasonably well under moderate collinearity (correlation coefficient $<|0.7|$ ) (Dormann et al., 2013). We verify that the correlation between any pairs of the time-varying predictor variables is less than 0.7 , except for the variables of the antecedent SPEI. We choose to keep the antecedent SPEI covering the different ranges of months to represent the different pre-fire drought conditions which are expected to play an important role for wildfires. For the winter-spring fire season, the pre-fire season starts in October and can range from 3 to 6 months for the start (January) and end (April) of the fire season, respectively. For the summer fire season, we use May as the start month of the pre-fire season and the pre-fire season ranges from 1 to 4 months for the start (July) and the end (September) of the summer fire season, respectively.

\subsubsection{Random-forest regression}

$\mathrm{RF}$ is an ensemble-learning algorithm built on decision trees. Each tree is built using the best split for each node among a subset of predictors randomly selected at the node (Liaw and Wiener, 2002). The best split criterion is based on selecting the variables at the nodes with the lowest Gini Index (GI), which is defined as GI $\left(t_{x}\left(x_{i}\right)\right)=1-\sum_{j=1}^{m} f\left(t_{x}\left(x_{i}\right), j\right)^{2}$, where $f\left(t_{x}\left(x_{i}\right), j\right)$ is the proportion of samples with the value $x_{i}$ belonging to leaf $j$ as node $t$. Two parameters can be adjusted to optimize the RF model, including the number of trees grown $\left(n_{\text {tree }}\right)$ and the number of predictors sampled for splitting at each node $\left(m_{\text {try }}\right)$. The RF regression model first draws $n_{\text {tree }}$ bootstrap samples from the original dataset. For each sample, at each node of a tree, $m_{\text {try }}$ predictors are randomly chosen from all the predictors and then the best split from among the predictors is determined at each node 


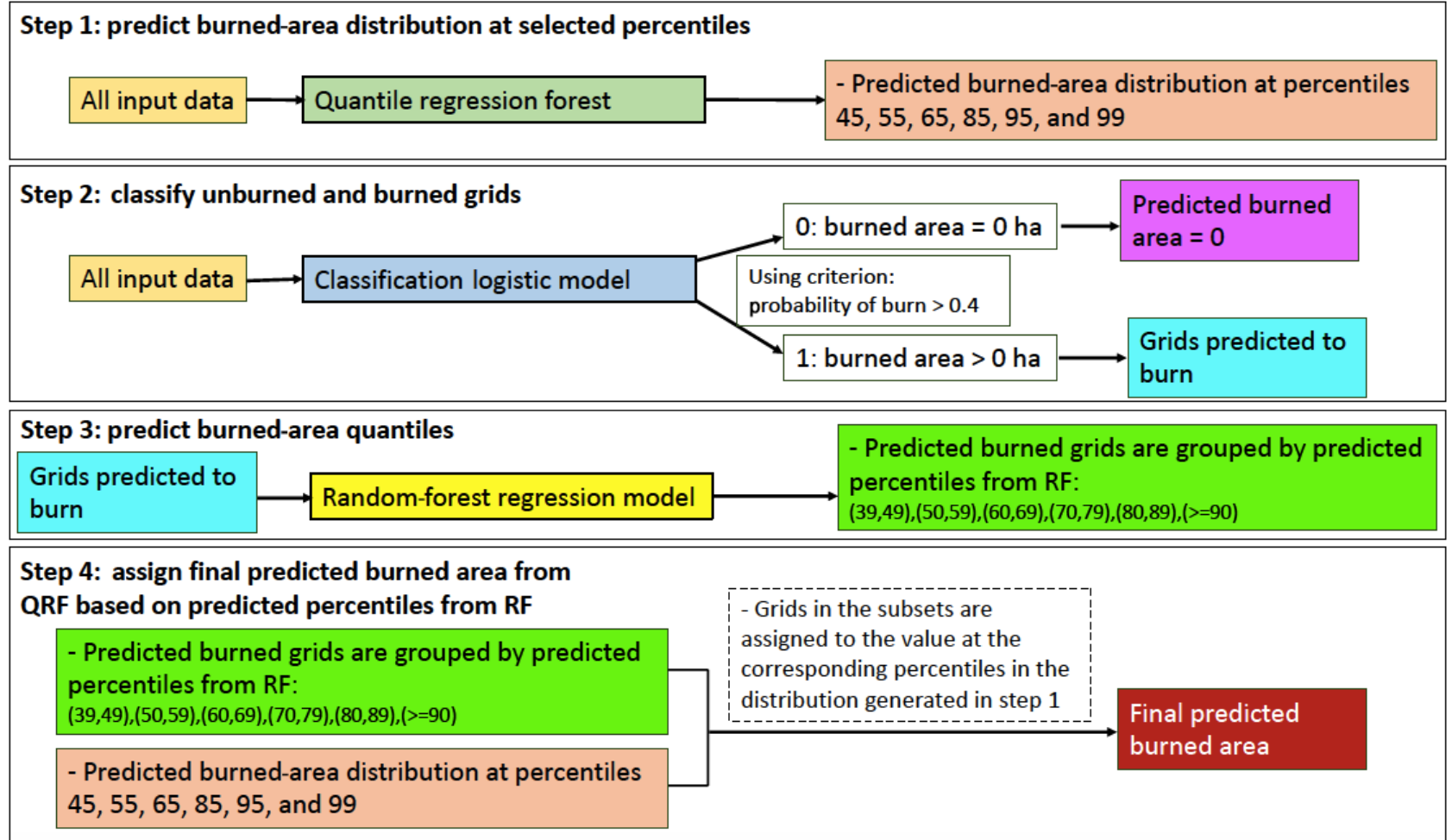

Figure 2. Illustration of the steps in the developed model. The model includes four steps and three machine learning algorithms, including a logistic model (dark blue) classifying a grid with non-zero burned area or not, a random-forest model (yellow) predicting percentiles of burned area, and a quantile regression forest (dark green) predicting conditional burned-area distributions.

according to GI. In this study, we have $n_{\text {tree }}$ of 1200 and $m_{\text {try }}$ of 8 for the winter-spring fire season and $n_{\text {tree }}$ of 1500 and $m_{\text {try }}$ of 7 for the summer fire season. As the length and characteristics of the two fire seasons are different, we use two sets of parameter configurations for the models of the two fire seasons which include different predictor variables (Sect. 2.2). This would ensure the prediction model is fully optimized for each fire season to obtain the best prediction accuracy. The predicted value of an observation is the average of the observed values belonging to the leaves of $n_{\text {tree }}$ trees. Here, we use the RF model to predict percentiles of burned area for the grids that are predicted to burn.

The benefit of applying the RF model is that it can provide the variable importance that measures the strength of individual predictors. The variable importance is measured by the increase in the mean square error (\%IncMSE) and the increase in node purities (IncNodePurity). The \%IncMSE is calculated by comparing the mean square error with and without permuting variables for each tree, and the variables with greater values of \%IncMSE are more important. As for the IncNodePurity, the changes in the residual sum of square (RSS) before and after the split are first derived at each split, and the final IncNodePurity of a variable is obtained by summing over the RSS of all the splits that include the variable over all trees. Thus, a larger IncNodePurity represents higher variable importance.

\subsubsection{Quantile regression forests}

QRFs are an extension of the RF (Meinshausen, 2006). QRF develops trees in the same way as RF, but instead of calculating the average of the values from leaves of the trees to obtain a single predicted value, the QRF estimates the conditional distribution of a target variable. The conditional distribution is calculated by averaging the conditional distributions from all the trees and the predicted quantiles or percentiles are derived from the final empirical distribution function. Here we choose to predict percentiles at 45, 55, 65, 75, 85, 95, and 99 as described above. These percentiles are selected because they can represent the full spectrum of fire sizes ranging from small to extremely large ones. The percentiles less than 45 are typically zero-burn, so the percentile of 45 is the lowest percentile that can possibly record both zero-burn and very small burned area for each grid.

\subsubsection{Logistic regression model}

Logistic regression is used to estimate the probability of wildfire occurrences in a grid cell by the statistical relationships between wildfire occurrences and the predictor vari- 
ables. Logistic regression is defined as $P_{i}=\frac{1}{1+e^{-\eta i}}$ and $\eta_{i}=$ $\beta_{0}+\beta_{1} X_{i 1}+\beta_{2} X_{i 2}+\ldots+\beta_{\rho} X_{i \rho}$, where $P i$ represents the probability of an occurrence of wildfire in a grid cell $i, \eta_{i}$ is the linear combination of the predictor variables weighted by their regression coefficients $(\beta), x_{i j}$ is the value of the predictor variable $j$ of the grid $i$, and $\beta_{0}$ is the constant. The logit function can be expressed as $\log \left(\frac{P}{1-P}\right)=x_{i}^{T} \beta$, where $\boldsymbol{x}_{i}^{T}$ is the vector of the predictor variables and $\boldsymbol{\beta}$ is the vector of the parameters. Values of $P$ greater than 0.4 are considered to be an occurrence of wildfires and those equal to or less than 0.4 are interpreted as nonoccurrence of wildfires. If a grid is classified not to burn, the predicted burned area is zero and that grid will not be processed further. On the other hand, if a grid is classified to burn, it would be analyzed by the RF model to predict the burned-area percentiles.

\subsection{Validation method}

We apply 10-fold cross-validation (CV) technique to evaluate the model performance and to avoid overfitting. The entire dataset (2002-2015) is randomly divided into 10 equal-sized splits. For each round of $\mathrm{CV}$, the model is trained with nine splits of the data and the trained model is then used to predict burned area at the remaining split.

Classification of burned or unburned grids is evaluated by the accuracy, precision, recall, and $F 1$ score. Precision and recall are defined in Eqs. (1) and (2):

$$
\begin{aligned}
& \text { Precision }=\frac{\text { True positive }}{\text { True positive }+ \text { False positive }}, \\
& \text { Recall }=\frac{\text { True positive }}{\text { True positive }+ \text { False negaitve }},
\end{aligned}
$$

where true positive is the number of burned grids correctly predicted, false positive is the number of grids which are unburned but are predicted as burned, and false negative is the number of grids that are burned but are predicted not to burn. The $F 1$ score measures a model's accuracy that combines precision and recall:

$$
F 1=\frac{2}{\text { recall }^{-1}+\text { precision }^{-1}} .
$$

$F 1$ score has a maximum value of 1 and a minimum value of 0 , and the higher $F 1$ indicates a higher balance between precision and recall. In addition to the aforementioned evaluation criteria, we use the receiver operating characteristic (ROC) curve, and the area under the curve (AUC) statistics to evaluate the classifier (Metz, 1978). The ROC curve shows how well the model can distinguish between the true positive rate (TPR) and the false positive rate (FPR), where TPR and
FPR are expressed by Eqs. (4) and (5):

True positive rate $=\frac{\text { True positive }}{\text { True positive }+ \text { False negative }}$,
False positive rate $=\frac{\text { False positive }}{\text { False positive }+ \text { True negative }}$.

The AUC is the area under the ROC curve, and it ranges from 0 to 1 . The greater the AUC, the better the discrimination between true positive and true negative.

Burned-area predictions are evaluated using statistical indicators such as the coefficient of determination $\left(R^{2}\right)$, mean absolute error (MAE), and root mean squared error (RMSE) between the predicted and observed wildfire burned areas. The evaluation is conducted for the winter-spring fire season and summer fire season separately. The prediction performance is also quantified in terms of the model ability in reproducing temporal variation in burned area for each grid and spatial patterns of burned area across all the grids of the study domain. Details on the calculation of the spatial and temporal correlations are described in the Supplement.

\section{Model validation and evaluation}

Here we present the validation results at two spatial scales: the grid scale of $0.5^{\circ} \times 0.5^{\circ}$ and the large-domain scale of $700 \mathrm{~km} \times 700 \mathrm{~km}$ corresponding to the size of the study domain (red box in Fig. 1). The grid-scale prediction of all possible outcomes (i.e., unburned, small burned, and large burned area) is a unique strength of our model. To the best of our knowledge, only few previously published studies included unburned and small burned grids into the prediction of wildfire burned area at a grid scale as fine as $0.5^{\circ} \times 0.5^{\circ}$. At the large-domain scale, we will compare our model performance with prior studies that predicted total burned area of an ecoregion or a country.

Table 2 lists a variety of statistics representing the model performance at the grid scale for the winter-spring fire season and summer fire season. The prediction performance of the classifier (i.e., the second step in the model) is evaluated by the ROC curves (Fig. S4), the AUC, accuracy, recall, precision, and $F 1$ score. The ROC curves of both fire seasons steer toward the upper left corner, indicating good performance of the model with a high detection rate of fires and a low false alarm. The AUCs for the two fire seasons are 0.82 and 0.83 . The accuracy and F- 1 score are 0.74 and 0.79 , respectively, for the winter-spring fire season and 0.74 and 0.77 for the summer fire season. These results indicate the model is capable of classifying burned grids and unburned grids with a good balance of recall and precision.

In terms of burned-area prediction at the grid scale, the $R^{2}$ reaches 0.42 and 0.40 for the winter-spring and summer fire season, respectively. MAE and RMSE are 1.13 and 8.37, respectively, for the winter-spring fire season, and 0.57 and 
Table 2. Model performance at grid level for the two fire seasons.

\begin{tabular}{lrrrrrrrr}
\hline Fire season & \multicolumn{8}{c}{ Evaluation metrics } \\
\cline { 2 - 9 } & Accuracy & Recall & Precision & $F 1$ score & AUC & $R^{2}$ & RMSE $\left(\mathrm{km}^{2}\right)$ & MAE $\left(\mathrm{km}^{2}\right)$ \\
\hline$F 1$ & 0.74 & 0.88 & 0.73 & 0.79 & 0.82 & 0.42 & 8.37 & 1.13 \\
F2 & 0.74 & 0.84 & 0.71 & 0.77 & 0.83 & 0.40 & 4.26 & 0.57 \\
\hline
\end{tabular}

(a)

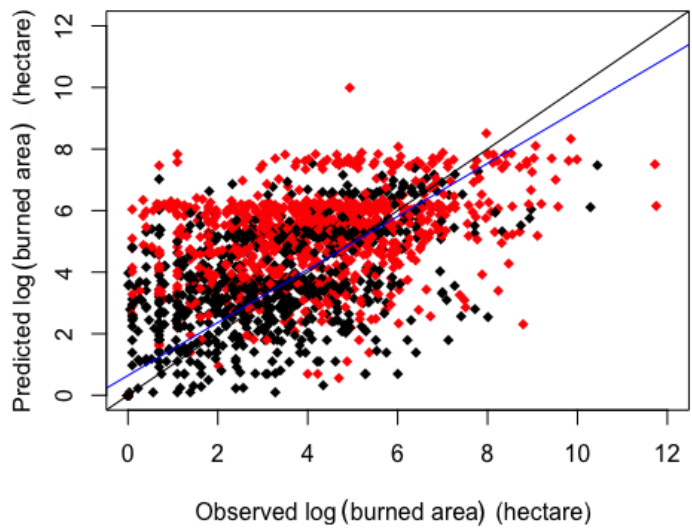

(b)

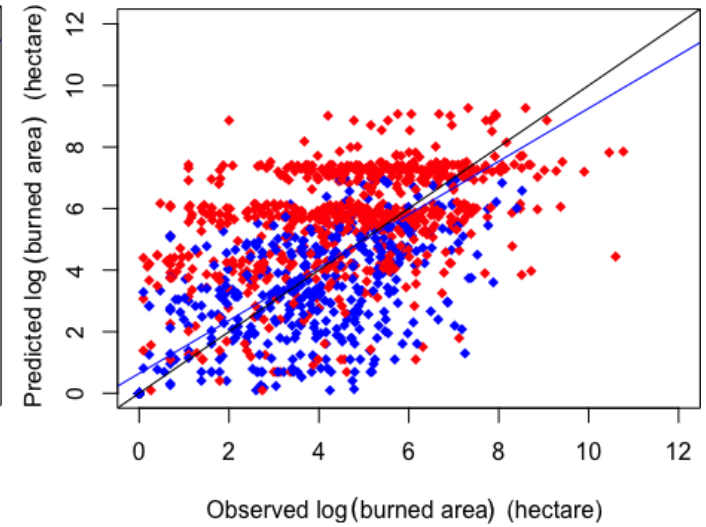

Figure 3. Comparison between observed and predicted logarithmic burned area (hectare) for the (a) winter-spring and (b) summer fire season in selected years: 2011 (red, year of the largest burned area), 2008 (blue, year with burned area close to the 14-year mean of its season), and 2014 (black, year with burned area close to the 14-year mean of its season). The black line represents the line of unity and the blue line is a best fit to the data by linear regression.

4.26 for the summer fire season. Before comparing these prediction statistics with previously published studies that predicted gridded burned area, it is important to note that the prediction accuracy will depend on the temporal scale (e.g., monthly or annual) and grid resolution at which the prediction is made. The larger spatiotemporal scales are expected to have a better prediction performance. Regarding the type of grids to be predicted, the most challenging case is the prediction including all possible outcomes of a given grid (i.e., unburned, with small burned areas, and with large burned areas). As fewer prior studies of a similar nature as ours predicted all possible outcomes (i.e., not only large burned areas but also unburned and small burned cases) at the grid level and none of these studies targeted the south central US, we choose to compare our model performance with previously published models that predicted gridded burned area in terms of the approaches, the temporal and spatial resolution, and the percent of variance explained by the model, regardless of their study regions, periods, methods, and predictors. Chen et al. (2016) used ocean climate indices to estimate annual burned area at the grid resolution of $1^{\circ} \times 1^{\circ}$, but their prediction was only for those grids with non-zero annual burned area. They achieved a prediction $R^{2}$ of less than 0.3 (correlation coefficient $r$ around 0.55) over the southern US (SUS). Using boosted regression trees, Liu and Wimberly (2015) obtained a higher $R^{2}$ of 0.76 between climate variables and burned area over the western US, but their investigation was limited to only extremely large fires ( $>405 \mathrm{ha}$ ) and was at a $1^{\circ} \times 1^{\circ}$ resolution and annual time step. Compared to these studies, our model targets a more challenging prediction (i.e., prediction at a finer spatial and temporal scale and for all the grids), yet achieves a comparable if not better performance at the grid scale.

Considering there are very few studies that predicted burned area by grids and at the same time considered unburned grids or grids with small fires, we extend the comparison to past studies predicting burned area of regions with similar spatial scales of $0.5^{\circ} \times 0.5^{\circ}$. Urbieta et al. (2015) used multiple linear regression (MLR) to predict the annual burned area of provinces and national forests in the southern countries of the European Union (EUMED) and Pacific western US (PWUSA), with the mean domain size of $108 \mathrm{~km} \times 108 \mathrm{~km}$. Their reported median $R^{2}$ is 0.28 for EUMED and 0.22 for PWUSA, smaller than our value (0.4). Using the MLR method, Carvalho et al. (2008) predicted monthly burned area of Portuguese districts of sizes ranging from $\sim 25 \mathrm{~km} \times 25 \mathrm{~km}$ to $100 \mathrm{~km} \times 100 \mathrm{~km}$, and their $R^{2}$ is between 0.43 and 0.80 . The better model performance was present only for some districts with evenly distributed burned area, whereas the districts with highly right-skewed burned-area distributions (Evora and Portalegre) had a prediction $R^{2}$ of 0.43 to 0.45 . Bedia et al. (2014) predicted 

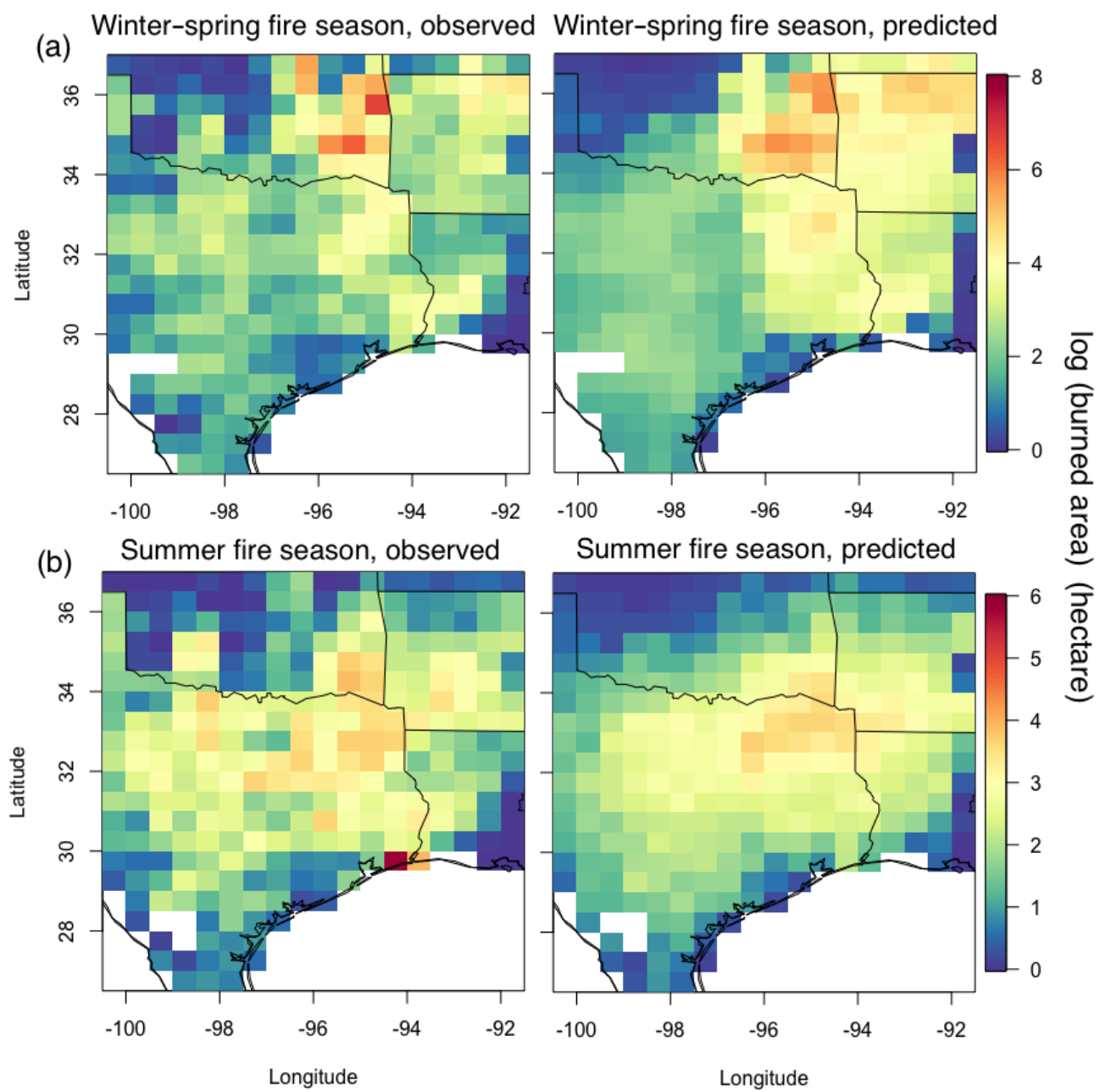

Figure 4. Map of monthly mean observed and predicted burned area averaged from 2002 to 2015 for the (a) winter-spring and (b) summer fire season.

monthly burned area of the phytoclimatic zones in Spain $(\sim 25 \mathrm{~km} \times 25 \mathrm{~km}$ to $100 \mathrm{~km} \times 100 \mathrm{~km})$ by using MARSs and obtained $R^{2}$ ranging from 0.01 to 0.37 . In comparison with these results, the $R^{2}$ of 0.42 and 0.40 that we achieve for the two fire seasons at a grid resolution of $0.5^{\circ} \times 0.5^{\circ}$ is a significant improvement for situations with unevenly distributed burned area. In addition, by predicting all possible outcomes for all the grids within a large domain, our model framework would be more flexible and practical to be applied to other domains.

The aforementioned statistics demonstrate the general capability of our four-step model in predicting gridded burned area over the study period. We select three specific years to further illustrate the model performance: 2011 with the largest domain-mean gridded burned area, and 2008 and 2014 with the domain-mean gridded burned area close to the 14-year mean for the winter-spring and summer fire season, respectively (Table S4). Figure 3 shows the selected CVpredicted and observed monthly burned area of these years for each fire season. The $R^{2}$ is $0.42,0.51$, and 0.66 for 2011 (combing both seasons), 2014 (the winter-spring season), and 2008 (the summer fire season), respectively, after excluding misclassified grids. MAE of 2011, 2014, and 2008 are 5.25, 0.77, 0.43 and RMSE are 21.06, 5.87, and 1.75. The detailed statistics of the model performance for each year are also shown in Table S5. The results show that the model has a better performance in predicting gridded burned area for normal years of 2008 and 2014 than for the exceptionally large wildfire year of 2011. Although larger MAE and RMSE are shown in 2011 (peak year), our model predicts significantly larger mean gridded burned area for the peak months. For 2011, the large burned area can be well modeled but the small burned area $(\log$ of burned area $<2)$ is overpredicted. This can be explained by the fact that the extremely hot and dry weather during 2011 caused fire-favorable conditions across the study domain. Due to the lack of reliable and detailed information about ignition and suppression, it is difficult for the model to discriminate between small and large 
fires given widespread extreme drought conditions across the whole domain during 2011 (Long et al., 2013; NielsenGammon, 2012).

The model performance is further evaluated in terms of its ability in reproducing the spatiotemporal patterns of monthly mean burned area for the two fire seasons (Fig. 4). The correlation coefficient between the 14-year mean observed and predicted burned area is 0.82 and 0.80 for the winter-spring and summer fire season, respectively. For the whole study period, more than $60 \%$ of the months have a spatial correlation larger than 0.5 for both fire seasons between the observed and predicted monthly burned area. It is noteworthy that such performance is achieved without introducing any coordinate variables like longitude or latitude as predictors. This indicates the chosen predictors contain sufficient information to capture the spatial heterogeneity of the environmental factors, and thus the framework of the model could be easily adopted for other regions, making it possible to be incorporated into climate models in future applications. Temporally, more than $70 \%$ of the grids have a correlation higher than 0.5 between the observed and predicted time series of burned area (combined the two fire seasons) (Fig. S5). These results demonstrate the model has a certain ability in predicting both spatial and temporal variation in the burned area at the grid scale across the study domain.

Even though bias may be introduced in the multi-step model, the developed four-step model can achieve higher accuracy and alleviate the issue of unevenly distributed dataset. To prove that, we compare the model performance of our four-step model with the prediction performance of simulations using MLR, only the RF model and another decisiontree-based ensemble machine learning algorithm called eXtreme Gradient Boosting (XGBoost) (Chen and Guestrin, 2016). The results are listed in Table $S 2$ and the description as well as the parameters of XGBoost are included in the Supplement (Table S3). Our four-step model has a lower MAE, which is $27 \%$ and $33 \%$ lower than the MLR model for the winter-spring and summer fire season, respectively. Compared to the RF model, our four-step model has a lower MAE by $15 \%$ and $19 \%$ for the winter-spring and summer fire season, respectively. Compared to the XGBoost model, the MAE from our four-step model is $11 \%$ and $15 \%$ lower for the two fire seasons. The distribution of MAE from the 10 -fold cross validation shows that our four-step model has a smaller median MAE but a larger range of MAE compared to other models (Fig. S6). In addition, the distribution of percentiles is more uniform than the distribution of the burned area, as shown in Fig. S2 and the skewness value. Details about the calculation of skewness are described in the Supplement. Larger positive skewness value indicates a more highly right-skewed distribution. The skewness of the burned area is 37.4 and 33.8 for the winter-spring and summer fire season, while the skewness of percentiles is 0.7 and 0.96 , showing that the strategy of the four-step model can effectively reduce unevenness of the distribution.
In addition to the grid-scale statistics, we evaluate the model performance at the large-domain scale by adding up all the grid-level predictions to obtain the total burned area of the study domain by months. Figure 5 shows the time series of the predicted total burned area over south central US in comparison to the observed ones for the two fire seasons. The domain-scale prediction explains $50 \%$ and $79 \%$ of the month-to-month variability of burned area for the winter-spring and summer fire season, respectively. Higher $R^{2}$ for the summer fire season can be explained by the stricter fire regulations during summer in the southern states, such as Texas (While and Hanselka, 2000). For the summer fire season, under strict fire regulations, environmental factors such as high temperature or low relative humidity can play a more important role in wildfire development. For the winterspring fire season, more human perturbations may be involved. As the human factor in the model does not capture such perturbation, less variability is explained by the model for the winter-spring season. MAE of the monthly burned area across the whole domain is $251.3 \mathrm{~km}^{2}$ for the winterspring fire season and $100.7 \mathrm{~km}^{2}$ for the summer fire season. Generally, our model is able to capture the interannual variability of burned area, and the prediction accuracy of our model in terms of $R^{2}$ is equivalent to or better than most of the published studies on the ecoregion scale or country scale, as shown in Table $\mathrm{S} 1$.

\section{Contributions of environmental factors to predicted wildfire burned area}

\subsection{Individual variable importance at grid scale}

Before discussing the environmental controls on wildfire burned area across the study domain, it is useful to understand the dominant factors controlling the burned area at the grid scale. One advantage of the random-forest approach is that it provides the variable importance metrics that can measure the power of predictor variables in the prediction. Figure 6 shows the top 14 predictors ranked by \% IncMSE to illustrate the intricate relationships between fires, weather, climate, and fuel. The top 14 variables are chosen because they represent the top quarter $(25 \%)$ of the selected predictor variables. In addition, a sensitivity test shows that the largest drop in the \%IncMSE occurs around the 15 th variable ranked by importance, as shown in Table S6. To ensure the reliability of the inferred importance of predicted factors, we conduct 50 times 10 -fold cross validation by randomizing the order of all the data each time. Figure S7 shows the distributions of \%IncMSE for each variable ranked by the median $\%$ IncMSE. Even though the numerical values of feature importance vary in different runs, the variable ranks by median values stay the same, indicating the robustness of the feature importance identified by the RF model. 

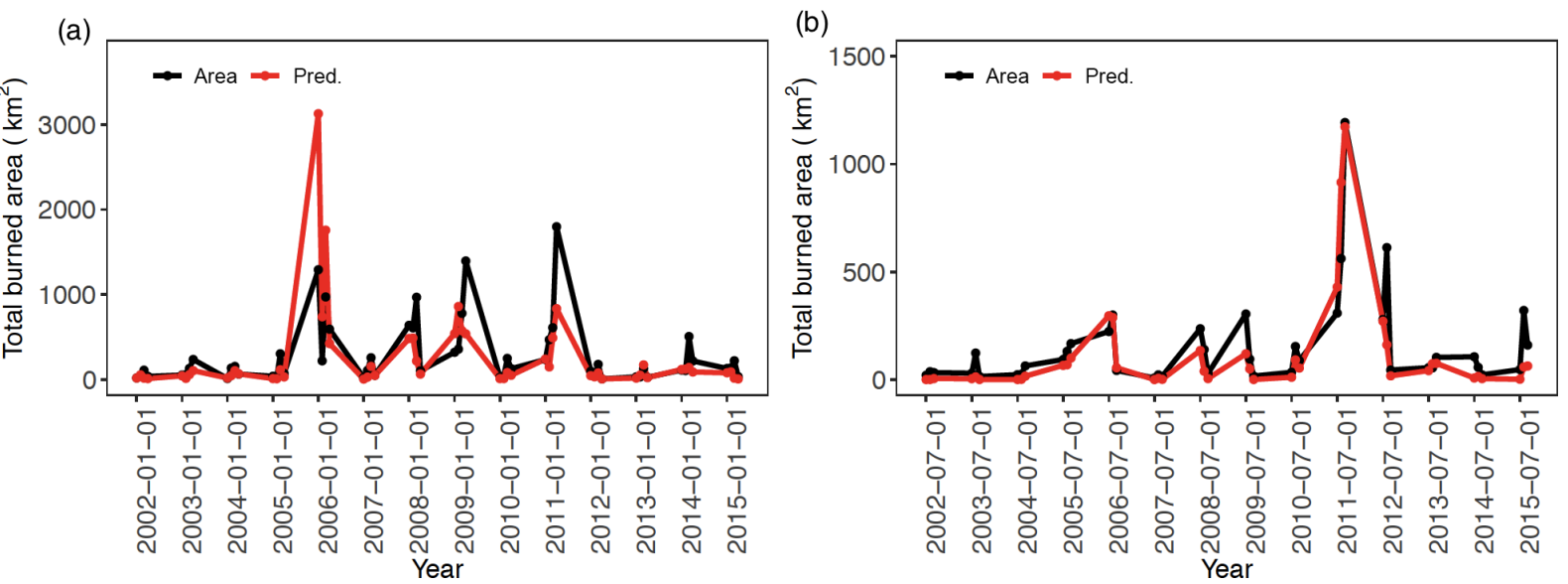

Figure 5. Time series of observed (black line) and predicted total burned area (red line) over south central US for the (a) winter-spring and (b) summer fire season.

(a)

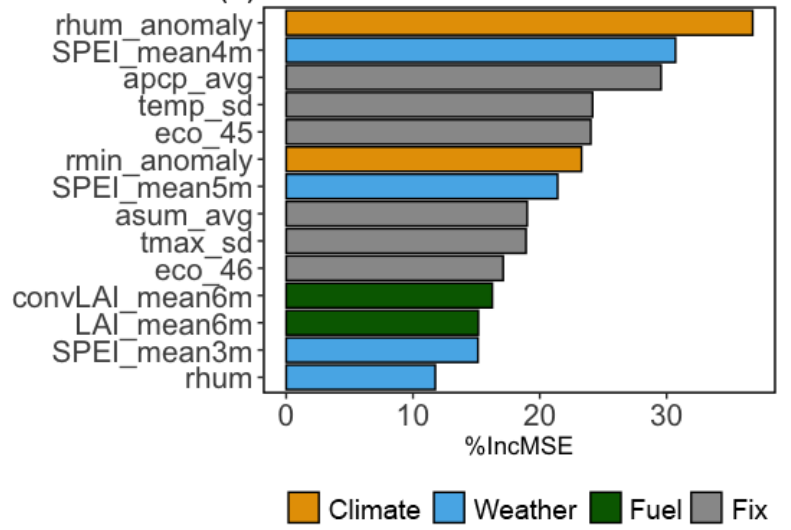

(b)

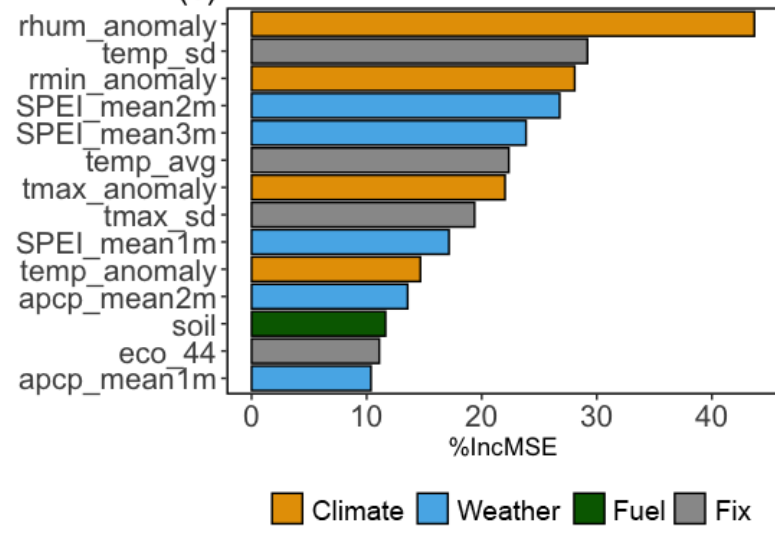

Figure 6. Relative importance of the top 14 variables presented by increase in mean square errors (\%IncMSE) for (a) the winter-spring fire season (b) summer fire season.

For both fire seasons, RH anomaly is the most important predictor of wildfire burned area at the grid scale (Fig. 6). This finding broadly supports past studies that highlighted the importance of RH on burned area (Riley et al., 2013; Ruthrof et al., 2016). Yet, our model particularly reveals the response of fire burned area to the changes in RH anomaly, which is a climate variable as opposed to a weather variable. "rhum" is the actual RH, which can vary by location and season, while RH anomaly measures the departure of rhum from its long-term average due to climate change and/or climate variability. For the study domain and time period, the correlation between RH anomaly and RH is 0.66 . Although they have a moderate correlation, their values have different physical meanings, and both of them are included in the model. For example, for grids with rhum of $\sim 70 \%$, rhum_anomaly can range from $-11.16 \%$ to $15.35 \%$. For the same rhum value of $\sim 70 \%$, positive rhum_anomaly indicates a relatively wetter condition and negative rhum_anomaly a relatively dryer condition compared to their long-term condition in the past. The variable importance metric highlights that $\mathrm{RH}$ anomaly, which indicates the changes in the fire-season $\mathrm{RH}$ relative to its historical climatology, ranks higher than the actual value of the fire-season $\mathrm{RH}$.

While both fire seasons have $\mathrm{RH}$ as the top driver of burned area, notable differences are found for the relative importance of other variables between the two fire seasons. For the summer fire season, temperature anomaly and maximum temperature anomaly are the other two climatic factors besides RH anomaly that are included in the top 14 variables. While RH anomaly and temperature anomaly are expected to correlate to some extent, the slope from a linear regression of $\mathrm{RH}$ anomaly ( $y$ ) on temperature anomaly $(x)$ is substantially greater (in absolute value) in the summer fire season (slope $=-3.7$ ) than that in the spring fire season (slope $=-0.89$ ) (Fig. S8). This highlights the stronger dependence of RH anomaly on temperature anomaly in the summer. Additionally, larger burned areas (75th percentile and above; black dots in Fig. S8) mainly occur under the 
condition of low RH anomaly and high temperature anomaly (bottom-right corner), in particular for the summer fire season. The results suggest that higher temperature coupled with lower relative humidity can cause drier fuel and create favorable conditions for fires to start, spread, and burn more intensely, in particular during the summer fire season (Williams et al., 2013; Holden et al., 2018).

For the winter-spring fire season specifically, the longterm averages of monthly total precipitation and monthly means of daily precipitation (apcp_avg and asum avg) are identified as the key climate variables (Fig. 6a). These two variables represent the precipitation normal, indicating the amount of available moisture that could affect fuel distributions and the tendency of fire activities (Keyser and Westerling, 2017; Westerling and Bryant, 2008). The averaged SPEI of the preceding 4 months is the second most important variable and the highest-ranked weather variable, which is even more important than the SPEI during the fire season. The averaged SPEI of the preceding 3 months and 5 months is also included in the top 14 variables. The 3-5 months' time lag coincidentally corresponds to the interval between the two fire seasons. Thus, our results indicate that burned area in this season is highly dependent on the pre-fire-season drought conditions, which is in agreement with prior studies (Scott and Burgan., 2005; Riley et al., 2013; Turco et al., 2017). To better understand how the changes in top variables affect the burned area, we use the partial dependence plots to show the marginal effect of a variable on the prediction performance of the built model (Friedman, 2001). Figure S9 shows the partial dependence plots of the top four variables (RH anomaly, SPEI_mean4m, apcp_avg, and temp_sd) for the winter-spring fire season. For RH anomaly, the fitted logarithmic burned area becomes larger if the $\mathrm{RH}$ anomaly is smaller than $2 \%$ (Fig. S9a). This change likely indicates the sensitivity of burned area to the fire-season moisture. The similar pattern is also shown in the partial dependence plot of the mean SPEI of the preceding 4 months (Fig. S9b). Larger fitted burned area is observed to be associated with the preceding SPEI smaller than zero, suggesting that burned area in this season is highly dependent on the pre-fire-season drought conditions. As for the average precipitation of 19792000 , the fitted burned area increases as the average precipitation increases (Fig. S9c). This implies the shift of fire regimes in that larger fires occur in the areas with more average precipitation in the past. For the standard deviation of temperature during 1979-2000, the fitted burned area declines dramatically when the standard deviation of temperature is larger $9 \mathrm{~K}$, suggesting the threshold effect of temperature variation on the burned area in the winter-spring fire season (Fig. S9d). In addition to the top four variables, which are all meteorological variables, the average of LAI and sum of neighboring LAI for months $t-1$ to $t-6$ are the only fuel variables that are selected among the top 14 variables in the winter-spring fire season (Fig. 6). Although these two variables rank below others among the top 14 variables, they are the fifth and sixth most important variables when excluding the fixed variables. Thus, when considering the importance of the time-varying variables, we can infer that fuel abundance together with drought conditions in the pre-fire season determine the amount of dry fuel, which likely exerts the primary controls of the burned area during the winter-spring fire season.

For the summer fire season, important weather variables include the average of monthly accumulated precipitation of the preceding 1 month and the mean SPEI of the preceding 1 month, 2 months, and 3 months (Fig. 6b). These variables are known to affect burned area by influencing fuel moisture. Consistently, fuel moisture as represented by soil moisture is identified as the only fuel variable among the top 14 variables in the summer fire season. These results suggest that fuel drying during the summer fire season driven by both increasing temperature and pre-fire season drought conditions is the pivotal process determining wildfire burned area in the summer. Similar to our findings, rising summer temperature under climate change was found to cause fast fuel dryness and increase fire activity in the western US (Williams et al., 2013; Holden et al., 2018). As the partial dependence plots show (Fig. S10), the large burned area is associated with low values of RH anomaly, minimum RH anomaly, the mean SPEI of the preceding 2 months, and long-term (1979-2000) standard deviation of temperature for the summer fire season. The fitted logarithmic burned area increases rapidly as the RH anomaly decreases toward zero and the increase in burned area reaches a maximum at $\mathrm{RH}$ anomaly of $-14 \%$ (Fig. S10a). Compared to the partial dependence plot for RH anomaly, the fitted burned area increases more rapidly with decreasing minimum RH anomaly (Fig. S10c). At below zero, the sensitivity of $\log$ (burned area) to the minimum $\mathrm{RH}$ anomaly is $0.04 \%^{-1}$ (Fig. S10c), while the corresponding sensitivity to RH anomaly is only $0.02 \%^{-1}$ (Fig. S10a). The stronger sensitivity of burned area to minimum RH anomaly indicates the stronger effect of extremely low humidity conditions on fire growth as compared with the mean RH conditions. For the standard deviation of temperature during 19792000, larger burned area is observed with a smaller standard deviation of temperature in the past. This suggests burned area would become larger for the grids with less variation in temperature in the summer. As for the mean SPEI of the preceding 2 months, we see an increase in fitted burned area at zero, with the largest increase at -1.8 , which supports the importance of the fuel drying process in the summer fire season. For both fire seasons, RH anomaly, mean SPEI of preceding months, and standard deviation of temperature for 1979-2000 are selected as the top four predictors, highlighting the common importance of these variables in the two seasons but with different thresholds and magnitudes in their effects on burned area. The difference in controlling factors for wildfires between the two fire seasons can be also demonstrated by the difference in correlation coefficients between burned area and predictors in the two seasons. The corre- 
lation between burned area and the average daily precipitation of months $t-1$ is -0.05 and -0.28 for the winterspring and summer fire season, respectively. The correlation between burned area and the average of SPEI of pre-fire seasons (months of $t-1$ to $t-3$ for winter-spring and $t-1$ to $t-2$ for summer) is -0.28 and -0.34 . Although lower moisture during the pre-fire season increases burned area for both fire seasons, the summer fire season has a stronger negative correlation between burned area and moisture during the pre-fire season. For the summer, since vegetation is relatively sufficient, fuel drying in the fire season and pre-fire season is a more important control for wildfire development. For the winter-spring fire season, as the vegetation amount is not as abundant as in the summer fire season, both fuel abundance and fuel drying in the pre-fire season are critical for wildfire development. The balance between the two factors may explain the weaker negative correlation between burned area and moisture in the pre-fire season for the winter-spring fire season.

Figure S11 shows the correlation coefficients between the predictor variables. Most of the important variables have weak to moderate correlations $(r<|0.7|)$ between each other. The exceptions are for the fixed climate variables (e.g., asum_avg vs. apcp_avg and temp_sd vs. tmax_sd) and the antecedent variables (e.g., SPEI_mean $4 \mathrm{~m}$ and SPEI_mean5m) for both fire seasons. This is expected because the long-term mean or standard deviation of the same types of meteorology do not change by time and the average of antecedent drought conditions (SPEI) may not vary a lot from including or excluding a single month. Although there is collinearity between the predictor variables, the logistic model and the RF model we use in this study are relatively insensitive to collinearity. Random forest as a machine learning tool is less unaffected by the issue of multicollinearity than traditional regression methods because the randomforest model randomly selects predictors used for each tree so that the probability of sampling strongly correlated variables in a particular tree is largely avoided (Siroky, 2009). To prove that the collinearity would not be an issue for our model, we calculate the variance inflation factor (VIF) for the random-forest model by a bootstrapping of seven predictors (the number of predictors used in each tree) out of all 58 potential predictors for 5000 times. Each sampling yields seven VIF values, and hence we can obtain a distribution of 35000 VIFs for 5000 samplings. Figure S12 shows the distribution of VIFs for all the predictors. The distribution has a median of 1.67 for the winter-spring and a median of 1.62 for the summer fire season. The distribution has about $96 \%$ of the VIF values smaller than 10 for both seasons, demonstrating the minimized multicollinearity in the random-forest model. In addition, we conduct a sensitivity test where the model uses predictor variables that have lower degrees of collinearity $(|r|<0.5)$, compared to the results using variables with higher degrees of collinearity $(|r|<0.7)$. The results show that removing the predictors that have a higher de- gree of collinearity causes larger biases in the classification of burned grids and the prediction of extremely large fires (Table S7). The overall MAE and RMSE are also slightly degraded in the sensitivity test. That is because although some variables may have a moderate correlation, they have different physical meanings and thus provide different predictive information. Therefore, we include all the variables in the model and allow the algorithms to choose the predictors for better performance.

Overall, the analysis of variable importance and partial dependence plots reveals the common and different characteristics of the wildfire development between the two fire seasons and show semi-quantitatively that drought conditions in the preceding months ( $3-5$ months for the spring fire season and 1-3 months for the summer fire season) may be more important than within-season conditions. Furthermore, we demonstrate that the effect of climate variability on burned area is consequential and even more influential than concurrent fire weather. This aspect has not been well documented or quantified in past studies for the south central US, partly due to a lack of long-term observations of wildfires over this region. Although we did not use long-term wildfire data (only 14 years of data used), with the 10 -fold cross-validation approach, the training dataset contains around 16277 samples for each fold. Such a large sample size is enough to capture the variability in wildfire activity and its response to the recent decadal climate if we assume wildfire relationships with the environmental factors contain a certain uniqueness for each individual grid. Considering that the majority of grids over the study domain are grassland/plain with a short fire interval ( $\sim 1$ year) (Barrett et al., 2010), the 14-year data are suitable for assessing fire variability for our study domain. Within this 14-year period, some regions (e.g., SE Texas) experienced the largest wildfire and the most severe single-year drought in the past 50 years (i.e., 2011 Texas wildfire). For future applications, our model can be applied to other regions with longer fire return intervals if more data are included. As the accuracy of our model is not quite high, uncertainties may exist in the rank of variable importance from the RF model. However, the selected top 14 variables all have physical linkages to wildfire burned area, and they have been discussed in this section and prior studies.

\subsection{Relative importance of environmental controls at large scale}

The variable importance metrics presented in the previous section reveal the relative importance of individual predictors. As mentioned before, these predictors are purposely selected from four broadly defined categories of environmental controls on wildfire burned area, namely climate, weather, fuel, and fixed geospatial. Here the climate category includes only variables of climate anomalies. The weather and fuel category are comprised of both fire season and antecedent weather and fuel conditions, respectively. The fixed geospa- 
tial category includes all the variables that do not change with time, including land types, ecoregion types, population, and 22-year means and standard deviations of meteorological variables (i.e., climate normals). Given that variables within the same category may work in conjunction to create conditions conducive to wildfires, in this section we examine the composite influence of predictors by category and quantify the contributions of these environmental controls to wildfire burned area. To do so, the prediction model developed from Section 3 is used to decompose the effect of different environmental controls across our study domain by perturbing all the variables belonging to one category at a time. The details of the decomposition method are described in the Supplement.

Figure S13 shows the time series of the contributions of different environmental controls on the burned area for the two fire seasons. The results show that the weather, fuel, climate, and fixed effects tend to increase the burned area for the large burn events (e.g., July 2011 in the summer fire season). To further investigate whether or not all factors would increase the burned area, we calculate the effect of each group in percentage by dividing the total burned area of the month, as shown in Fig. S14. For the months with the large burned area (e.g., January 2006 and September 2011), weather, fuel, climate, and fix effect tend to increase burned area. This is consistent with the results in Fig S8. This is not the case for some months with the relatively small burned area, such as February 2012 where the interaction $(-143 \%)$, climate $(-1.4 \%)$, and weather effect $(-33.8 \%)$ reduce the burned area but fuel $(12 \%)$ and fix effect $(266 \%)$ together increase the burned area. As the number of variables in each environmental control category is different, we first normalize the absolute contribution of one environmental control by the number of variables in that category and then compare each category's contribution in scaled absolute percentage, which is defined as the normalized absolute contribution of one environmental control divided by the summation of normalized absolute contributions over all the categories. The scaled absolute percentage represents the average contribution from all the variables in one environmental category, so the variable importance presented here is not affected by the number of variables we include in each category. Figure S15 shows the time series of the scaled absolute percentage of each category. For both fire seasons, on average, the climate and fixed categories have larger contributions to the burned area than other categories, although their relative importance varies by time. Figure 7 and Table S8 present the mean effect of the environmental controls where the scaled absolute percentage of each category of environmental controls is averaged over the whole study periods. Figure 7 clearly shows that the climate category on average has the largest contribution to the burned area for both fire seasons, with the mean scaled absolute contribution of $33 \%$ and $35 \%$ for the winter-spring and summer fire season, respectively. This suggests climate variability is a significant factor to explain wildfire burned area over our

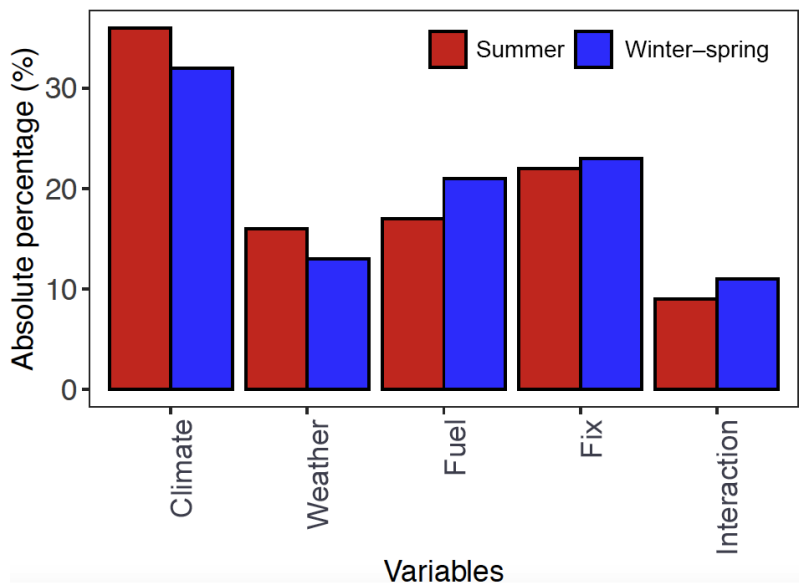

Figure 7. The mean scaled absolute percentage of the environmental controls for the winter-spring (blue) and summer fire season (red).

study domain. This result is consistent with previous studies that demonstrated the significant contribution of changing climate to the total burned area of ecoregions in the western US (Littell et al., 2009; Swetnam and Anderson, 2008; Yue et al., 2013). For example, increasing temperature and earlier spring snowmelt due to climate change are highly associated with increased large wildfire activity in the western US (Westerling et al., 2006). Another study showed that fireyear climate variables such as average spring temperature are predictive variables that could improve the predicting probability of high-severity fires in the western US (Keyser and Westerling, 2017). Additionally, the fixed effect that comprises the geospatial variables and past climatology is ranked as the second most important control (Fig. 7). This is consistent with the findings of Keyser and Westerling (2017), which revealed the importance of long-term climate normals in controlling large fire occurrences in the western US.

Comparing the effects of the environmental controls between the two fire seasons, we find the fuel effect is significantly more important in the winter-spring fire season, while weather and climate effects are more substantial in the summer fire season. This can probably be explained by the different characteristics of the two fire seasons. As biomass growth is relatively limited in the winter-spring fire season, the effect of fuel (mainly from vegetation in the pre-fire growing season) is likely the limiting factor for wildfires. On the other hand, vegetation is relatively sufficient during the summer growing fire season and thus fuel abundance would not be a constraint of wildfires (Littell et al., 2009; Zhang et al., 2014). Yet, fire weather that determines fuel moisture is a substantial factor in the summer fire season (Fig. 7).

The above analysis represents the relative importance of the environmental controls at the large-domain scale. At the grid scale, we calculate the average of variable importance (\% IncMSE) from RF (Sect. 3.1.1) of each category and use 
the category-averaged variable importance to represent the relative importance at the grid scale (Table S9). Climate variables are found to have the largest importance in controlling burned area at the grid scale for the two fire seasons, with the mean \%IncMSE of 12.09 and 19.18 for the winter-spring and summer fire season, respectively. This is consistent with the results based on the large-domain scale. Fuel effect outweighs weather effect on the grid scale in the winter-spring fire season, while weather effect is more important in the summer fire season, both consistent with the aforementioned analysis based on the large-scale domain (Table S9). However, the fixed effect estimated at the grid scale is less important than at the large-scale domain (Table S9), and this is partly due to how these variables are encoded in the model. Fixed variables consist of past climatology and geospatial variables (i.e., land use, ecoregion, and population). The geospatial variables, except population, are encoded as categorical variables in the prediction model. For example, forest ecoregion is coded as 0 or 1 for a given grid, with 0 representing non-forest and 1 representing a forest. For such an encoding method, each categorical variable (e.g., forest vs. non-forest) tends to have a smaller relative importance score, compared to the relative importance score of other variables encoded by continuous values. As RF measures the effect of a specific split on the improvement in model performance and aggregates the improvement of all the splits with a specific variable, the fragmented scores for each category are likely smaller than the scores reflecting all of the categories. Therefore, for the relative importance at the grid level measured by RF, the effect of a single geospatial variable such as a land type on the burned area is trivial. When we average the relative importance of all the fixed variables including many small scores, the resulting average importance still becomes a small value.

\section{Concluding remarks}

We present a model consisting of multiple machine learning methods to predict monthly burned area over south central US at $0.5^{\circ} \times 0.5^{\circ}$ grid cells. The prediction model is able to alleviate the issue of unevenly distributed burned area and consequently improves the model capability of predicting large burned area at a finer spatial and temporal scale. The predicted burned area shows a good agreement with the observed burned area at both the grid and large-domain scale. At the grid scale, the classification component of the model achieves an AUC of 0.82 and 0.83 for the winterspring and summer fire season, respectively. With respect to burned-area prediction, a CV $R^{2}$ of 0.42 and 0.40 is achieved for the winter-spring and summer fire season, respectively, which makes a significant improvement to the prediction for the cases with unevenly distributed burned area compared to most past studies. Our four-step model is able to predict the spatial patterns of the 14-year mean burned area, with a correlation coefficient between mean observed and predicted burned area of 0.82 and 0.80 for the winter-spring and summer fire season, respectively. Throughout the study period, more than $60 \%$ of the months have a spatial correlation larger than 0.5 . When comparing the time series of observed and predicted burned area of each grid across the study domain, over $70 \%$ of the grids have a correlation coefficient larger than 0.5 . At the large-domain scale, the prediction model can explain $50 \%$ and $79 \%$ of the interannual variability of wildfire burned area for the winter-spring and summer fire season, respectively. The validation results demonstrate that the model has certain skills in predicting monthly burned area at both grid scale and large-domain scale.

Although the model shows a better ability to predict monthly burned area at both grid scale and large-domain scale than past studies of similar nature, it has several limitations. First, errors might be propagated through our serial model and lead to lower accuracy. For example, when the burned grids are predicted not to burn, low bias occurs because the burned grids are not able to enter step 3. Similarly, the inclusion of unburned grids in step 3 will introduce a positive bias. Second, random forest or quantile regression forest cannot predict burned area greater than it observes before, i.e., the maximum burned area of any of the available grids. We should point out that such limitation is applicable only at grid level and that upper limit is taken from all available grids of the whole training period, which we refer to as the global upper limit per grid. For example, the global upper limit is $514 \mathrm{~km}^{2}$ per grid for the winter-spring fire season, and $238 \mathrm{~km}^{2}$ per grid for the summer fire season. For a single grid, burned-area prediction can be greater than what this grid had experienced before by learning from other grids, although the prediction per grid cannot exceed the global upper limit. Figure S16 shows an example for a randomly selected grid box. For this grid, the model predicts the largest burned area on February 2008, consistent with observed burned area. This demonstrates that any single grid can predict burned area larger than the grid maximum by learning from other grids, and as such a larger total burned area for the domain can be predicted by the model under future climate change. In addition, we verify that the global upper limit is a sufficiently large value because of the intrinsically skewed nature of burned-area distributions. Figure S17 shows the distribution of gridded burned area for year 2011, an extremely severe fire year for the study domain, in comparison to the distribution of all other years during 2002-2015. It can be seen that the majority of the burned areas for the extreme year are still within the range of the observed burned area in 20022015 , with only two grids having burned areas larger than the global upper limit from 2002 to 2015 (excluding 2011). The total burned area of those exceedance grids only accounts for $20 \%$ of total burned area for 2011, which is within the stated uncertainty range of our prediction model. Third, as machine learning models are data-driven, data quality of different input datasets may introduce biases as the input datasets come 
from a wide variety of data sources and errors in one type of input data may cause sequential errors in the prediction. For instance, biases in the NARR meteorological data can further lead to incorrect fire-meteorology relationships learned by the model. Fourth, this study focuses on the effects of environmental controls on burned area under present-day human management practices and human activity. As such, we do not examine the effects of time-varying socioeconomic factors on burned area, such as human actions that affect wildfires through ignition, suppression, or modifying fuel distribution (Andela et al., 2017; Bowman et al., 2011; Mann et al., 2016; Syphard et al., 2007). Given that human activity is one of the major controls on fire activity, future work is needed to better understand the role of human activity engaged with climate change and its implications for wildfire control. Finally, the pre-defined parameters that are used in the model, including the percentiles and subgroups, may induce uncertainties. To understand the related uncertainties, we switch the pre-defined percentiles but fix the subgroups in the first sensitivity experiment (Table S10). In this experiment, the last three quantiles are changed to the median values between a new set of lower and upper bounds. The second experiment is conducted by changing the number of subgroups, their ranges, and the corresponding percentiles. Generally, changing pre-defined parameters has little effect on overall MAE for the two fire seasons, but the MAE of large burned area becomes larger and the standard deviation of the predicted values becomes smaller. Thus, the pre-defined parameters mostly affect the spread of the predictions and the prediction of large burned areas. Despite this sensitivity, the prediction model with the chosen settings (i.e., percentiles and subgroups) is able to predict burned area at $0.5^{\circ} \times 0.5^{\circ}$ grid scale and achieves a higher prediction accuracy compared to prior studies.

The individual variable importance from the RF model is analyzed and discussed. For both fire seasons, RH anomaly followed by drought conditions in the preceding months (35 months for the winter-spring fire season and 1-3 months for the summer fire seasons) are the two top variables in predicting burned area at the grid scale. For the winter-spring fire season specifically, the average of LAI and sum of neighboring LAI of the preceding 6 months are the only two fuel variables that are identified in the top 14 variables, and they rank fifth and sixth when only considering time-varying variables. The findings suggest that fuel abundance together with drought conditions during the pre-fire season regulates the abundance of dry fuel, which is the primary control of fire burned area during the winter-spring seasons. For the summer fire season, temperature anomalies, the average of monthly accumulated precipitation of the preceding 1 month, and fire season soil moisture are important variables in predicting burned area. This suggests that temperature variability and pre-fire season drought can speed up fuel drying and lead to wildfires in the summer. The model highlights the effect of climate variability on burned area as well as the dif- ferent environmental controls of burned area for the two fire seasons.

Besides the relative importance of individual predictors, we also analyze the relative importance of the environmental controls by four categories - climate, weather, fuel, and fixed geospatial - at both the grid and large-domain scale. The relative importance of these factors is generally consistent at the two scales. The climate variable on average has the largest contribution to the burned area for both fire seasons, with the mean scaled absolute contribution of $33 \%$ and $35 \%$ to the burned area at the large-domain scale for the winter-spring and summer fire season, respectively. For the winter-spring fire season, the fuel variable on average has larger importance compared to the weather variable, while for the summer fire season, the weather variable is more dominant than the fuel variable. The difference in the relative importance of the environmental controls between the large-domain scale and grid scale mainly lies in the predominance of the fixed effect. The fixed effect is ranked as the second most important control at the large-domain scale, but it is not as important at the grid scale.

Predictor variables representing climate variability are ranked as the most important variables by our prediction model. This reinforces the importance of regional climate variability as the key driver for wildfires that have been revealed by past studies for other regions, yet our study is among the first to explicitly demonstrate such importance for the south central US. For this region, our model further reveals drought conditions in the preceding 3-5 months of a fire season as an important predictor for wildfire burned area. This antecedent timescale would be valuable for fire management and fire prediction in the future. While the relative importance of environmental controls is largely consistent between the large-domain scale $(\sim 700 \mathrm{~km} \times 700 \mathrm{~km})$ and the grid scale $(\sim 50 \mathrm{~km} \times 50 \mathrm{~km})$, our analysis at different spatial scales would help estimate how the relationship between wildfire and environmental controls will change as a function of spatial scales, which could be used to improve wildfire modeling and prediction in different models.

Code availability. Model code is available upon request to the first author.

Data availability. All dataset used in this study are publicly accessible online at https://doi.org/10.7910/DVN/LRPDAA (last access: 30 September 2020, Wang, 2020).

Supplement. The supplement related to this article is available online at: https://doi.org/10.5194/acp-20-11065-2020-supplement. 
Author contributions. SCW and YW conceived the research idea. SCW wrote the initial draft of the paper and performed the analyses and model development. All authors contributed to the interpretation of the results and the preparation of the paper.

Competing interests. The authors declare that they have no conflict of interest.

Acknowledgements. This work was funded by the State of Texas as part of the program of the Texas Air Research Center (grant number: 117UHH0175A). The authors thank the AI for Earth grant from Microsoft for providing computation resources. Yuxuan Wang acknowledges additional support from NOAA Atmospheric Chemistry and Carbon Cycle Program (NA19OAR4310177). The contents do not necessarily reflect the views and policies of the sponsor nor does the mention of trade names or commercial products constitute endorsement or recommendation for use. We acknowledge the NCEP Reanalysis data provided by the NOAA/OAR/ESRL PSL, Boulder, Colorado, USA, from their website at https://psl.noaa.gov/ (last access: 22 March 2018).

Financial support. This research has been supported by the Texas Air Research Center (grant no. 117UHH0175A) and NOAA Atmospheric Chemistry and Carbon Cycle Program (NA19OAR4310177).

Review statement. This paper was edited by Yafang Cheng and reviewed by four anonymous referees.

\section{References}

Amatulli, G., Camia, A., and San-Miguel-Ayanz, J.: Estimating future burned areas under changing climate in the EUMediterranean countries, Sci. Total Environ., 450/451, 209-222, https://doi.org/10.1016/j.scitotenv.2013.02.014, 2013.

An, H., Gan, J., and Cho, S. J.: Assessing Climate Change Impacts on Wildfire Risk in the United States, Forests, 6, 3197-3211, https://doi.org/10.3390/f6093197, 2015.

Andela, N., Morton, D. C., Giglio, L., Chen, Y., Werf, G. R. van der, Kasibhatla, P. S., DeFries, R. S., Collatz, G. J., Hantson, S., Kloster, S., Bachelet, D., Forrest, M., Lasslop, G., Mangeon, S., Melton, J. R., Yue, C., and Randerson, J. T.: A humandriven decline in global burned area, Science, 356, 1356-1362, https://doi.org/10.1126/science.aal4108, 2017.

Baboo, S. and Devi, R.: An Analysis of Different Resampling Methods in Coimbatore, District, Global Journal of Computer Science and Technology, 10, 61-66, 2010.

Balshi, M. S., McGUIRE, A. D., Duffy, P., Flannigan, M., Walsh, J., and Melillo, J.: Assessing the response of area burned to changing climate in western boreal North America using a Multivariate Adaptive Regression Splines (MARS) approach, Glob. Change Biol., 15, 578-600, https://doi.org/10.1111/j.13652486.2008.01679.x, 2009.
Barbero, R., Abatzoglou, J. T., Larkin, N. K., Kolden, C. A., and Stocks, B.: Climate change presents increased potential for very large fires in the contiguous United States, Int. J. Wildland Fire, 24, 892-899, https://doi.org/10.1071/WF15083, 2015.

Barrett, S., Havlina, D., Jones, J., Hann, W., Frame, C., Hamilton, D., Schon, K., Demeo, T., Hutter, L., and Menakis, J.: Interagency Fire Regime Condition Class Guidebook, United States Forest Service and U.S. Department of the Interior, The Nature Conservancy, U.S., 98-125, 2010.

Bedia, J., Herrera, S., and Gutiérrez, J. M.: Assessing the predictability of fire occurrence and area burned across phytoclimatic regions in Spain, Nat. Hazards Earth Syst. Sci., 14, 53-66, https://doi.org/10.5194/nhess-14-53-2014, 2014.

Bowman, D. M. J. S., Balch, J. K., Artaxo, P., Bond, W. J., Carlson, J. M., Cochrane, M. A., D'Antonio, C. M., DeFries, R. S., Doyle, J. C., Harrison, S. P., Johnston, F. H., Keeley, J. E., Krawchuk, M. A., Kull, C. A., Marston, J. B., Moritz, M. A., Prentice, I. C., Roos, C. I., Scott, A. C., Swetnam, T. W., van der Werf, G. R., and Pyne, S. J.: Fire in the Earth System, Science, 324, 481-484, https://doi.org/10.1126/science.1163886, 2009.

Bowman, D. M. J. S., Balch, J., Artaxo, P., Bond, W. J., Cochrane, M. A., D’Antonio, C. M., DeFries, R., Johnston, F. H., Keeley, J. E., Krawchuk, M. A., Kull, C. A., Mack, M., Moritz, M. A., Pyne, S., Roos, C. I., Scott, A. C., Sodhi, N. S., and Swetnam, T. W.: The human dimension of fire regimes on Earth, J. Biogeogr., 38, 2223-2236, https://doi.org/10.1111/j.13652699.2011.02595.x, 2011.

Camia, A. and Amatulli, G.: Weather Factors and Fire Danger in the Mediterranean, Earth Observation of Wildland Fires in Mediterranean Ecosystems, 71-82, https://doi.org/10.1007/9783-642-01754-4_6, 2010.

Carvalho, A., Logan, Miranda, A., and Borrego, C.: Fire activity in Portugal and its relationship to weather and the Canadian Fire Weather Index System, Int. J. Wildland Fire, 17, 328-338, https://doi.org/10.1071/WF07014, 2008.

Chen, J. M. and Black, T. A.: Defining leaf area index for non-flat leaves, Plant Cell Environ., 15, 421-429, https://doi.org/10.1111/j.1365-3040.1992.tb00992.x, 1992.

Chen, T. and Guestrin, C.: XGBoost: A Scalable Tree Boosting System, in Proceedings of the 22nd ACM SIGKDD International Conference on Knowledge Discovery and Data Mining, Association for Computing Machinery, San Francisco, California, USA, 785-794, 2016.

Chen, Y., Morton, D. C., Andela, N., Giglio, L., and Randerson, J. T.: How much global burned area can be forecast on seasonal time scales using sea surface temperatures?, Environ. Res. Lett., 11, 045001, https://doi.org/10.1088/17489326/11/4/045001, 2016.

Dormann, C. F., Elith, J., Bacher, S., Buchmann, C., Carl, G., Carré, G., Marquéz, J. R. G., Gruber, B., Lafourcade, B., Leitão, P. J., Münkemüller, T., McClean, C., Osborne, P. E., Reineking, B., Schröder, B., Skidmore, A. K., Zurell, D., and Lautenbach, S.: Collinearity: a review of methods to deal with it and a simulation study evaluating their performance, Ecography, 36, 27-46, https://doi.org/10.1111/j.1600-0587.2012.07348.x, 2013.

Duane, A., Kelly, L., Gijohann, K., Batllori, E., McCarthy, M., and Brotons, L.: Disentangling the Influence of Past Fires on Subsequent Fires in Mediterranean Landscapes, Ecosystems, 22, 1338-1351, https://doi.org/10.1007/s10021-019-00340-6, 2019. 
Fang, L., Yang, J., Zu, J., Li, G., and Zhang, J.: Quantifying influences and relative importance of fire weather, topography, and vegetation on fire size and fire severity in a Chinese boreal forest landscape, Forest Ecol. Manag., 356, 2-12, https://doi.org/10.1016/j.foreco.2015.01.011, 2015.

Fann, N., Alman, B., Broome, R. A., Morgan, G. G., Johnston, F. H., Pouliot, G., and Rappold, A. G.: The health impacts and economic value of wildland fire episodes in the U.S.: 2008-2012, Sci. Total Environ., 610-611, 802-809, https://doi.org/10.1016/j.scitotenv.2017.08.024, 2018.

Fernandes, P. M., Monteiro-Henriques, T., Guiomar, N., Loureiro, C., and Barros, A. M. G.: Bottom-Up Variables Govern Large-Fire Size in Portugal, Ecosystems, 19, 1362-1375, https://doi.org/10.1007/s10021-016-0010-2, 2016.

Flannigan, M. D., Logan, K. A., Amiro, B. D., Skinner, W. R., and Stocks, B. J.: Future area burned in Canada, Climate Change, 72, 1-16, https://doi.org/10.1007/s10584-005-5935-y, 2005.

Flannigan, M. D., Krawchuk, M. A., Groot, W. J. de, Wotton, B. M., and Gowman, L. M.: Implications of changing climate for global wildland fire, Int. J. Wildland Fire, 18, 483-507, https://doi.org/10.1071/WF08187, 2009.

Fréjaville, T. and Curt, T.: Seasonal changes in the human alteration of fire regimes beyond the climate forcing, Environ. Res. Lett., 12, 035006, https://doi.org/10.1088/1748-9326/aa5d23, 2017.

Friedman, J. H.: Greedy Function Approximation: A Gradient Boosting Machine, Ann. Stat., 29, 1189-1232, 2001.

Gudmundsson, L., Rego, F. C., Rocha, M., and Seneviratne, S. I.: Predicting above normal wildfire activity in southern Europe as a function of meteorological drought, Environ. Res. Lett., 9, 084008, https://doi.org/10.1088/1748-9326/9/8/084008, 2014.

Heilman, W. E., Potter, B. E., and Zerbe J. I.: Regional climate change in the southern United States: The implications for wildfire occurrence in the Productivity and Sustainability of Southern Forest Ecosystems in a Changing Environment, New York, Springer-Verlag, 683-699, 1998.

Heyerdahl, E. K., McKenzie, D., Daniels, L. D., Hessl, A. E., Littell, J. S., and Mantua, N. J.: Climate drivers of regionally synchronous fires in the inland northwest (1651-1900), Int. J. Wildland Fire, 17, 40-49, 2008.

Holden, Z. A., Swanson, A., Luce, C. H., Jolly, W. M., Maneta, M., Oyler, J. W., Warren, D. A., Parsons, R., and Affleck, D.: Decreasing fire season precipitation increased recent western US forest wildfire activity, P. Natl. Acad. Sci. USA, 115, E8349E8357, https://doi.org/10.1073/pnas.1802316115, 2018.

Homer, C., Dewitz, J., Jin, S., Xian, G., Costello, C., Danielson, P., Gass, L., Funk, M., Wickham, J., Stehman, S., Auch, R., and Riitters, K.: Conterminous United States land cover change patterns 2001-2016 from the 2016 National Land Cover Database, ISPRS J. Photogramm. Remote Sens., 162, 184-199, https://doi.org/10.1016/j.isprsjprs.2020.02.019, 2020.

Jaffe, D., Hafner, W., Chand, D., Westerling, A., and Spracklen, D.: Interannual Variations in $\mathrm{PM}_{2.5}$ due to Wildfires in the Western United States, Environ. Sci. Technol., 42, 2812-2818, https://doi.org/10.1021/es702755v, 2008.

Jones, J., Saginor, A., and Smith, B.: 2011 Texas Wildfires: Common Denominators of Home Destruction, College Station, TX, Texas A\&M Forest Service, 2013.

Keane, R. E., Reinhardt, E. D., Scott, J., Gray, K., and Reardon, J.: Estimating forest canopy bulk density using six indirect methods, Canadian J. Forest Res., 35, 724-739, https://doi.org/10.1139/x04-213, 2005.

Keyser, A. and Westerling, A. L.: Climate drives inter-annual variability in probability of high severity fire occurrence in the western United States, Environ. Res. Lett., 12, 065003, https://doi.org/10.1088/1748-9326/aa6b10, 2017.

Kirchmeier-Young, M. C., Gillett, N. P., Zwiers, F. W., Cannon, A. J., and Anslow, F. S.: Attribution of the Influence of HumanInduced Climate Change on an Extreme Fire Season, Earth's Future, 7, 2-10, https://doi.org/10.1029/2018EF001050, 2018.

Krawczyk, B.: Learning from imbalanced data: open challenges and future directions, Prog. Artif. Intell., 5, 221-232, https://doi.org/10.1007/s13748-016-0094-0, 2016.

Krueger, E. S., Ochsner, T. E., Carlson, J. D., Engle, D. M., Twidwell, D., and Fuhlendorf, S. D.: Concurrent and antecedent soil moisture relate positively or negatively to probability of large wildfires depending on season, Int. J. Wildland Fire, 25, 657668, https://doi.org/10.1071/WF15104, 2016.

Liaw, A. and Wiener, M.: Classification and Regression by randomForest, R News, 2, 18-22, 2002.

Littell, J. S., McKenzie, D., Peterson, D. L., and Westerling, A. L.: Climate and wildfire area burned in western U.S. ecoprovinces, 1916-2003, Ecol. Appl., 19, 1003-1021, https://doi.org/10.1890/07-1183.1, 2009.

Liu, Y., Goodrick, S. L., Stanturf, J. A.: Future U.S. wildfire potential trends projected using a dynamically downscaled climate change scenario, Forest Ecol. Manag., 294, 120-135, https://doi.org/10.1016/j.foreco.2012.06.049, 2013.

Liu, Z. and Wimberly, M. C.: Climatic and Landscape Influences on Fire Regimes from 1984 to 2010 in the Western United States, PLOS ONE, 10, e0140839, https://doi.org/10.1371/journal.pone.0140839, 2015.

Long, D., Scanlon, B. R., Longuevergne, L., Sun, A. Y., Fernando, D. N., and Save, H.: GRACE satellite monitoring of large depletion in water storage in response to the 2011 drought in Texas, Geophys. Res. Lett., 40, 3395-3401, https://doi.org/10.1002/grl.50655, 2013.

Mann, M. L., Batllori, E., Moritz, M. A., Waller, E. K., Berck, P., Flint, A. L., Flint, L. E., and Dolfi, E.: Incorporating Anthropogenic Influences into Fire Probability Models: Effects of Human Activity and Climate Change on Fire Activity in California, PLOS ONE, 11, e0153589, https://doi.org/10.1371/journal.pone.0153589, 2016.

Meinshausen, N.: Quantile Regression Forests, J. Mach. Learn. Res., 7, 983-999, 2006.

Mesinger, F., DiMego, G., Kalnay, E., Mitchell, K., Shafran, P. C., Ebisuzaki, W., Jović, D., Woollen, J., Rogers, E., Berbery, E. H., Ek, M. B., Fan, Y., Grumbine, R., Higgins, W., Li, H., Lin, Y., Manikin, G., Parrish, D., and Shi, W.: North American Regional Reanalysis, B. Am. Meteorol. Soc., 87, 343-360, https://doi.org/10.1175/BAMS-87-3-343, 2006.

Metz, C. E.: Basic principles of ROC analysis, Semin. Nucl. Med., 8, 283-298, https://doi.org/10.1016/s0001-2998(78)80014-2, 1978.

Mocko, D.: NASA/GSFC/HSL, NLDAS Noah Land Surface Model L4 Monthly Climatology $0.125 \times 0.125$ degree V002, Goddard Earth Sciences Data and Information Services Center (GES DISC), https://doi.org/10.5067/U5BAYF8R76IK, 2013. 
Morgan, P., Heyerdahl, E. K., and Gibson, C. E.: Multi-season climate synchronized forest fires throughout the 20th century, Northern Rockies, USA, Ecology, 89, 717-728, 2008.

Myneni, R., Knyazikhin, Y., and Park, T.: MCD15A2H MODIS/Terra + Aqua Leaf Area Index/FPAR 8-day L4 Global 500m SIN Grid V006, NASA EOSDIS Land Processes DAAC, https://doi.org/10.5067/MODIS/MCD15A2H.006, 2015.

Nielsen-Gammon, J. W.: The 2011 Texas Drought, Texas Water J., 3, 59-95, 2012.

Nunes, M. C. S., Vasconcelos, M. J., Pereira, J. M. C., Dasgupta, N., Alldredge, R. J., and Rego, F. C.: Land Cover Type and Fire in Portugal: Do Fires Burn Land Cover Selectively?, Landscape Ecol., 20, 661-673, https://doi.org/10.1007/s10980-005-0070-8, 2005.

Omernik, J. M. (Ed.): Ecoregions: A spatial framework for environmental management, in: Biological Assessment and Criteria: Tools for Water Resource Planning and Decision Making, Lewis Publishers, Boca Raton, FL, 49-62, 1995.

Omernik, J. M. and Griffith, G. E.: Ecoregions of the conterminous United States: evolution of a hierarchical spatial framework, Environ. Manage., 54, 1249-1266, https://doi.org/10.1007/s00267014-0364-1, 2014.

Parisien, M.-A., Parks, S. A., Krawchuk, M. A., Flannigan, M. D., Bowman, L. M., and Moritz, M. A.: Scale-dependent controls on the area burned in the boreal forest of Canada, 1980-2005, Ecol. Appl., 21, 789-805, https://doi.org/10.1890/10-0326.1, 2011.

Parks, S. A., Parisien, M.-A., and Miller, C.: Spatial bottom-up controls on fire likelihood vary across western North America, Ecosphere, 3, art12, https://doi.org/10.1890/ES11-00298.1, 2012.

Pausas, J. G. and Keeley, J. E.: A Burning Story: The Role of Fire in the History of Life, BioScience, 59, 593-601, https://doi.org/10.1525/bio.2009.59.7.10, 2009.

Pellegrini, A. F. A., Anderegg, W. R. L., Paine, C. E. T., Hoffmann, W. A., Kartzinel, T., Rabin, S. S., Sheil, D., Franco, A. C., and Pacala, S. W.: Convergence of bark investment according to fire and climate structures ecosystem vulnerability to future change, Ecol. Lett., 20, 307-316, https://doi.org/10.1111/ele.12725, 2017.

Peters, D. P. C., Pielke, R. A., Bestelmeyer, B. T., Allen, C. D., Munson-McGee, S., and Havstad, K. M.: Crossscale interactions, nonlinearities, and forecasting catastrophic events, P. Natl. Acad. Sci. USA, 101, 15130-15135, https://doi.org/10.1073/pnas.0403822101, 2004.

Riley, K. L., Abatzoglou, J. T., Grenfell, I. C., Klene, A. E., and Heinsch, F. A.: The relationship of large fire occurrence with drought and fire danger indices in the western USA, 1984-2008: the role of temporal scale, Int. J. Wildland Fire, 22, 894-909, https://doi.org/10.1071/WF12149, 2013.

Ruthrof, K. X., Fontaine, J. B., Matusick, G., Breshears, D. D., Law, D. J., Powell, S., and Hardy, G.: How droughtinduced forest die-off alters microclimate and increases fuel loadings and fire potentials, Int. J. Wildland Fire, 25, 819-830, https://doi.org/10.1071/WF15028, 2016.

Scott, J. H. and Burgan, R. E.: Standard fire behavior fuel models: a comprehensive set for use with Rothermel's surface fire spread model, Gen. Tech. Rep. RMRS-GTR-153, Fort Collins, CO: U.S. Department of Agriculture, Forest Service, Rocky Mountain Re- search Station, 72 pp., https://doi.org/10.2737/RMRS-GTR-153, 2005.

Short, K. C.: A spatial database of wildfires in the United States, 1992-2011, Earth Syst. Sci. Data, 6, 1-27, https://doi.org/10.5194/essd-6-1-2014, 2014.

Short, K. C.: Spatial wildfire occurrence data for the United States, 1992-2015, Forest Service Research Data Archive, 4th Edn., https://doi.org/10.2737/RDS-2013-0009.4, 2017.

Siroky, D. S.: Navigating Random Forests and related advances in algorithmic modeling, Statist. Surv., 3, 147-163, https://doi.org/10.1214/07-SS033, 2009.

Slocum, M. G., Beckage, B., Platt, W. J., Orzell, S. L., and Taylor, W.: Effect of Climate on Wildfire Size: A Cross-Scale Analysis, Ecosystems, 13, 828-840, https://doi.org/10.1007/s10021010-9357-y, 2010.

Sousa, P. M., Trigo, R. M., and Pereira, M. G.: Different approaches to model future burnt area in the Iberian Peninsula, Agr. Forest Meteorol., 202, 11-25, https://doi.org/10.1016/j.agrformet.2014.11.018, 2015.

Spracklen, D. V., Mickley, L. J., Logan, J. A., Hudman, R. C., Yevich, R., Flannigan, M. D., and Westerling, A. L.: Impacts of climate change from 2000 to 2050 on wildfire activity and carbonaceous aerosol concentrations in the western United States, J. Geophys. Res.-Atmos., 114, D20301, https://doi.org/10.1029/2008JD010966, 2009.

Steel, Z. L., Safford, H. D., and Viers, J. H.: The fire frequencyseverity relationship and the legacy of fire suppression in California forests, Ecosphere, 6, 1-23, https://doi.org/10.1890/ES1400224.1, 2015.

Steele-Feldman, A., Reinhardt, E., and Parsons, R. A.: Fuels Management-How to Measure Success: Conference Proceedings, USDA Forest Proceedings, 283-291, 2006.

Swetnam, T. W. and Anderson, R. S.: Fire Climatology in the western United States: introduction to special issue, Int. J. Wildland Fire, 17, 1-7, https://doi.org/10.1071/WF08016, 2008.

Syphard, A. D., Radeloff, V. C., Keeley, J. E., Hawbaker, T. J., Clayton, M. K., Stewart, S. I., and Hammer, R. B.: Human Influence on California Fire Regimes, Ecol. Appl., 17, 1388-1402, https://doi.org/10.1890/06-1128.1, 2007.

Turco, M., Hardenberg, J. von, AghaKouchak, A., Llasat, M. C., Provenzale, A., and Trigo, R. M.: On the key role of droughts in the dynamics of summer fires in Mediterranean Europe, Sci. Rep., 7, p. 81, https://doi.org/10.1038/s41598-017-00116-9, 2017.

Urbieta, I. R., Zavala, G., Bedia, J., Gutierrez, J. M., San MiguelAyanz, J., Camia, A., Keeley, J. E., and Moreno, J. M.: Fire activity as a function of fire-weather seasonal severity and antecedent climate across spatial scales in southern Europe and Pacific western USA, Environ. Res. Lett., 10, 114013, https://doi.org/10.1088/1748-9326/10/11/114013, 2015.

U.S. Census Bureau: Population Estimates, 2010 Census Population density, available at: https:/www.census.gov/geographies/ mapping-files/time-series/geo/tiger-line-file.2010.html (last access: 1 September 2018), 2010.

Vicente-Serrano, S. M., Beguería, S., and López-Moreno, J. I.: A Multiscalar Drought Index Sensitive to Global Warming: The Standardized Precipitation Evapotranspiration Index, J. Clim., 23, 1696-1718, https://doi.org/10.1175/2009JCLI2909.1, 2009. 
Wang, S.-C., Wang, Y., Estes, M., Lei, R., Talbot, R., Zhu, L., and Hou, P.: Transport of Central American Fire Emissions to the U.S. Gulf Coast: Climatological Pathways and Impacts on Ozone and $\mathrm{PM}_{2.5}$, J. Geophys. Res.-Atmos., 123, 8344-8361, https://doi.org/10.1029/2018JD028684, 2018.

Wang, S.-C.: Replication Data for: Quantifying the effects of environmental factors on wildfire burned area in the south central US using integrated machine learning techniques, available at: https://doi.org/10.7910/DVN/LRPDAA, last access: 30 September 2020 .

Watson, D. J.: Comparative Physiological Studies on the Growth of Field Crops: I. Variation in Net Assimilation Rate and Leaf Area between Species and Varieties, and within and between Years, Ann. Botany, 11, 41-76, https://doi.org/10.1093/oxfordjournals.aob.a083148, 1947.

Westerling, A. L.: Increasing western US forest wildfire activity: sensitivity to changes in the timing of spring, Philos. T. R. Soc. B, 371, 20150178, https://doi.org/10.1098/rstb.2015.0178, 2016.

Westerling, A. L. and Bryant, B. P.: Climate change and wildfire in California, Climatic Change, 87, 231-249, https://doi.org/10.1007/s10584-007-9363-z, 2008.

Westerling, A. L., Hidalgo, H. G., Cayan, D. R., and Swetnam, T. W.: Warming and Earlier Spring Increase Western U.S. Forest Wildfire Activity, Science, 313, 940-943, https://doi.org/10.1126/science.1128834, 2006.

Westerling, A. L., Turner, M. G., Smithwick, E. A. H., Romme, W. H., and Ryan, M. G.: Continued warming could transform Greater Yellowstone fire regimes by mid21st century, P. Natl. Acad. Sci. USA, 108, 13165-13170, https://doi.org/10.1073/pnas.1110199108, 2011.

White, L. D. and Hanselka, C. W.: Prescribed Range Burning in Texas, Texas AgriLife Extension Service Publication, College Station, Texas, 2000.
Williams, P. A., Allen, C. D., Macalady, A. K., Griffin, D., Woodhouse, C. A., Meko, D. M., Swetnam, T. W., Rauscher, S. A., Seager, R., Grissino-Mayer, H. D., Dean, J. S., Cook, E. R., Gangodagamage, C., Cai, M., and McDowell, N. G.: Temperature as a potent driver of regional forest drought stress and tree mortality, Nat. Clim. Change, 3, 292-297, https://doi.org/10.1038/nclimate1693, 2013.

Xia, Y., Mitchell, K., Ek, M., Sheffield, J., Cosgrove, B., Wood, E., Luo, L., Alonge, C., Wei, H., Meng, J., Livneh, B., Lettenmaier, D., Koren, V., Duan, Q., Mo, K., Fan, Y., and Mocko, D.: Continental-scale water and energy flux analysis and validation for the North American Land Data Assimilation System project phase 2 (NLDAS-2): 1. Intercomparison and application of model products, J. Geophys. Res.-Atmos., 117, D03109, https://doi.org/10.1029/2011JD016048, 2012.

Yue, X., Mickley, L. J., Logan, J. A., and Kaplan, J. O.: Ensemble projections of wildfire activity and carbonaceous aerosol concentrations over the western United States in the mid-21st century, Atmos. Environ., 77, 767-780, https://doi.org/10.1016/j.atmosenv.2013.06.003, 2013.

Yue, X., Mickley, L. J., Logan, J. A., Hudman, R. C., Martin, M. V., and Yantosca, R. M.: Impact of 2050 climate change on North American wildfire: consequences for ozone air quality, Atmos. Chem. Phys., 15, 10033-10055, https://doi.org/10.5194/acp-1510033-2015, 2015.

Zhang, X., Kondragunta, S., and Roy, D. P.: Interannual variation in biomass burning and fire seasonality derived from geostationary satellite data across the contiguous United States from 1995 to 2011, J. Geophys. Res.- Biogeo., 119, 1147-1162, https://doi.org/10.1002/2013JG002518, 2014.

Zubkova, M., Boschetti, L., Abatzoglou, J. T., and Giglio, L.: Changes in Fire Activity in Africa from 2002 to 2016 and Their Potential Drivers, Geophys. Res. Lett., 46, 7643-7653, https://doi.org/10.1029/2019GL083469, 2019. 